\title{
Supplier surfing: competition and consumer behavior in subscription markets
}

\author{
Curtis R. Taylor*
}

I explore the practice of offering subscribers enticements to switch suppliers. This type of competition is natural in subscription markets for homogeneous goods and services. Efficiency is impaired because subscribers are induced to expend resources changing suppliers. Subscription markets are fully competitive only when three or more firms serve the industry. In this case, the price offered to switchers is below cost, while nonswitchers pay a premium. Each firm earns rent on its customer base, but zero expected profit on each new subscriber it attracts. When firms can track switching behavior, consumers may change suppliers in order to establish reputations.

Jim Eaves ... ran up several thousand dollars of credit card debt in the mid 1990 s when he was out of work after a heart attack. ... Mr. Eaves hadn't paid much attention to all the confusing credit card solicitation letters crammed into his mailbox, but a bookkeeper friend told Mr. Eaves to look closer, and he found offers to transfer all that high-rate debt to the other cards at a rate lower than 7\%. The lenders' hope, of course, was that Mr. Eaves and his debt would jump once, settle back in and then six months later submit to a big ratcheting up of interest charges. Instead, ... [he] ... became what's known as a card surfer, jumping through five low-rate credit cards, and whittling his debt down to $\$ 2,000$. "I'm beating them at their own game," Mr. Eaves said.

- Bailey and Kilman, The Wall Street Journal, February 20, 1998, p. A1.

\section{Introduction}

- In this article I investigate competition and consumer behavior in subscription markets, like the general-purpose credit card market featured in the opening excerpt. ${ }^{l}$ Specifically, I explore the common marketing practice of offering subscribers enticements to switch suppliers. I show that this type of price discrimination is the natural mode of competition in subscription markets and prevails even when the industry in question is fully competitive and all firms earn zero economic profit. ${ }^{2}$ In addition, while price discrimination in monopolistic markets often enhances efficiency (see Varian, 1985), the type of price discrimination studied here undermines it because consumers are induced to spend time and effort switching suppliers.

* Duke University; crtaylor@econ.duke.edu.

I thank Gregory Besharov, Joe Harrington, Thomas Jeitschko, Preston McAfee, Canice Prendergast, Lars Stole, Steve Tadelis, and my students, Wolfgang Koehler and Oksana Loginova, as well as many seminar participants and two anonymous referees for helpful comments and suggestions. Financial support was provided by the Alfred P. Sloan Foundation, the National Science Foundation (grant no. SBR-9810858), and the Bush Program in Public Policy at Texas A\&M University.

${ }^{1}$ Brito and Hartley (1995) show that it can be rational for a consumer to carry a modest balance on a credit card despite its relatively high interest rate because of the transactions cost of obtaining a conventional loan. The analysis offered here complements this finding because card surfers don't even pay the high rates.

${ }^{2}$ Other studies involving price discrimination in zero-profit industries include Borenstein (1985), Locay and Rodriguez (1992), and Armstrong and Vickers (2001). 
The main difference between subscription markets and conventional retail settings is that firms in subscription markets deliver a flow of goods or services directly to their customers. Hence, transactions in subscription markets are not anonymous. In particular, each firm knows whether a given consumer is one of its current subscribers and can price discriminate on the basis of this knowledge. For instance, Bailey and Kilman (1998) report that $60 \%$ of all Visa and MasterCard solicitations include a "teaser," (low introductory rate) on balances transferred from a card issued by another bank.

While subscriptions are not a new form of retailing, recent technological advances have given rise to a variety of new subscription services, including internet access, satellite television, and wireless communications, among others. Also, industrial deregulation has spawned significant levels of competition in traditional subscription markets such as long-distance telephony and banking. ${ }^{3}$

Other goods and services sold via subscription include newspapers and magazines, healthclub memberships, and many household services. It is very common in these markets for firms to offer initial discounts, trial memberships, free installation and equipment, or other bonuses to new subscribers. For example, the leading long-distance carriers all offer significant enticements to customers who switch to their service. According to Schwartz (1997, p. 237), "Reflecting this competitive jockeying, in 1994 about $20 \%$ of all customers changed their long-distance company."

The goods or services sold in a subscription market are often quite homogeneous. Nevertheless, a consumer must generally bear nontrivial transactions costs in order to change suppliers. These switching costs give individuals incentives to remain with the same supplier over time, granting firms a degree of monopoly power over their base of subscribers. For example, over half of the $80,000,000$ households subscribing to AT\&T in 1997 paid its standard long-distance rate, which was at least $33 \%$ higher than what they could have obtained by switching, according to Keller (1997). ${ }^{4}$

With the exception of Chen (1997), the study of markets with consumer switching costs has focused exclusively on anonymous retail settings where explicit price discrimination is not possible. A firm operating in such a setting can implicitly price discriminate against the consumers attached to it by charging a high price to anyone buying its products, but it will not attract new customers. In a subscription market, by contrast, a firm can attract new customers with a low "introductory" price while simultaneously exploiting its monopoly power over its current subscribers. As Fudenberg and Tirole (2000) point out, this type of price discrimination, in which the offer made to a consumer depends on his past behavior, does not fit into the textbook classifications (e.g., Varian, 1989). In addition, behavior-based price discrimination, while of growing importance, has received limited theoretical attention to date. ${ }^{5}$

Besides this study, there are currently four theoretical articles on behavior-based price discrimination: Chen (1997), Fudenberg and Tirole (2000), Villas-Boas (1999), and Shaffer and Zhang (2000). Chen (1997) first studied the practice of enticing customers to switch. Specifically, he studied a two-period duopoly model in which consumer switching costs are uniformly distributed. The model presented here allows for an arbitrary number of firms, an arbitrary number of periods, any distribution of switching costs possessing a nondecreasing hazard function, and persistent consumer heterogeneity. Each of these generalizations either extends Chen's findings in a significant way or provides completely new insights. For instance, it is shown here that subscription markets are truly competitive only when three or more firms serve the industry, suggesting that duopoly is a pathological industrial structure in subscription markets. Another novel finding

${ }^{3}$ The Telecommunications Act of 1996 may ultimately foster competition in subscription markets for local telephony and cable television as well. See Economides (1999) and Schwartz (1997). In addition, more than a dozen states have enacted legislation intended to open their electricity markets to competition.

${ }^{4}$ The pioneering articles on markets with consumer switching costs are Klemperer (1987a, 1987b, 1987c). See also von Weizsacker (1984). Klemperer (1995) and Farrell and Klemperer (forthcoming) provide excellent surveys of the switching-cost literature.

${ }^{5}$ An alternative explanation for introductory offers in the context of a two-period monopoly model is provided by van Acker and Reyniers (1995).

- RAND 2003. 
is that if firms can track consumer behavior over time, then a subscriber will have a strategic incentive to change suppliers. In other words, he may change suppliers in order to establish a reputation as a switcher and secure better future offers from his suppliers. Since the consumers in Chen's model are all stochastically identical and-in any case-have only one opportunity to change suppliers, strategic switching does not occur in the setting he considers.

Fudenberg and Tirole and Villas-Boas study behavior-based price discrimination in a different setting from the one analyzed here. Rather than investigating a subscription market for a homogeneous good in the presence of consumer switching costs, these authors study the market for a horizontally differentiated product where there are no explicit costs of changing suppliers. Specifically, Fudenberg and Tirole analyze a two-period version of the classic linear-city duopoly model in which consumer tastes are distributed on an interval between the two firms serving the market. In the second period, the firms recognize the customers they served previously and can price discriminate accordingly. Villas-Boas also studies a linear-city duopoly with customer recognition, but he assumes that the firms are infinitely lived while demand is composed of overlapping generations of consumers who live for two periods.

While both Fudenberg and Tirole and Villas-Boas present some results similar in spirit to findings offered here, there are important differences between the linear-city and switching-cost paradigms. For example, if a consumer in a linear city experiences a large-enough taste shock between periods, then it is efficient for him to switch suppliers. By contrast, changing suppliers is never efficient in a homogeneous-goods market with switching costs. Also, a firm operating in a linear-city setting always earns positive profit from the consumers located near it. In the setting studied here, however, a firm makes an introductory offer that is below cost and subsequently recoups this "investment" by charging repeat purchasers a premium. The question as to which of the two settings is more appropriate depends largely on the market under study. In some subscription markets (e.g., newspapers), product differentiation is undoubtedly important, while in others, the products are quite homogeneous and the transactions costs associated with switching suppliers can be nontrivial. ${ }^{6}$ Similar differences also exist between the model considered here and the static model of differentiated products studied by Shaffer and Zhang (2000). Interestingly, these authors show that when products are differentiated and demands are asymmetric, it can be optimal for a firm to offer discounts to its "loyal" customers.

Two key assumptions are maintained throughout the article and are worth mentioning at this point. First, the switching cost of each individual varies randomly from period to period, reflecting the capricious demands on his time, effort, and other resources. In other words, high switchingcost realizations signify busy periods, and low realizations signify slack ones. In addition, the realization of an individual's switching cost in any period is taken to be private nonverifiable information. ${ }^{7}$ The second important assumption is that firms and consumers have very limited commitment power; i.e., only short-term contracts are considered. Hence, firms can commit to prices for only a single period, and consumers cannot commit not to switch suppliers. ${ }^{8}$ Indeed, the inefficient switching that occurs in the equilibrium of this model derives largely from the inability to commit. If suppliers could commit to future prices and consumers could commit not to switch, then the firms would become static Bertrand competitors, offering long-term contracts in which they promise to price at marginal cost forever. In this light, the recent trend in the credit

\footnotetext{
${ }^{6}$ The significance of switching costs have been verified empirically in a number of subscription markets, including auto insurance (Schlesinger and von der Schulenburg, 1993), interstate long distance (Knittel, 1997), bank deposits (Sharpe, 1997), and credit cards (Stango, 2001).

${ }^{7}$ Nilssen (1992) studies a model with some similarities to the one presented here. A crucial difference, however, is that there is no uncertainty in his model. This generates very different equilibrium behavior. For instance, no consumers ever switch suppliers in the setting Nilssen considers.

${ }^{8}$ In some subscription markets, introductory offers may span several billing cycles; e.g., credit card teaser rates typically last six months. There is, however, no particular reason to suppose that the relevant period length corresponds to the length of a billing cycle. A subscriber who changes suppliers may have the same low level of switching costs for some time. If his new supplier ramps up its price too soon, then the consumer will simply switch again. A "period" in the context of this article should be regarded as the amount of time over which a consumer's level of switching cost is likely to remain constant.
}

O RAND 2003. 
card industry to offer customers "lifetime low rates" is intriguing. It should be noted, however, that card issuers still typically retain the right to cancel and/or sell accounts, and card holders certainly do not commit not to switch.

The basic model is presented in the next section. The duopoly case $(n=2)$ is then explored in Section 3 and the general case $(n>2)$ in Section 4 . In both cases, I show that there exists a unique subgame-perfect equilibrium outcome of the game. While these outcomes differ across the two settings, they are similar in structure. In both cases, equilibrium prices are independent of market shares and do not change over time except in the last period. ${ }^{9}$ Also, in both cases, consumers in equilibrium follow a stationary reservation-cost rule that leads them to change suppliers whenever their switching-cost realizations fall below a critical level. The simplicity of equilibrium strategies makes it possible to characterize the evolution of market shares and derive closed-form solutions for the equilibrium payoff functions. At date $t$, a firm's market share is a convex combination of its initial (date-zero) market share and a symmetric market share of $1 / n$. Moreover, as $t$ tends to infinity, all market shares converge to $1 / n .^{10}$

The $n=2$ and $n>2$ cases are considered separately because, as noted above, subscription markets are truly competitive only when there are at least three firms. Under duopoly, a consumer has only two choices: he may remain with his current supplier and pay its high price or switch to the other firm and pay its low price. Hence, one firm's high price competes with the other's low price and vice versa. This considerably softens competition and permits duopolists to make positive economic profit in equilibrium. On the other hand, if $n>2$, then there are always at least two firms vying for any consumer willing to leave his current supplier. In this case, the firms bid away all expected profit by offering introductory prices that are below cost. As noted, firms do earn positive rents from their current subscribers. These rents, however, are offset exactly by the upfront "investment" that was required to attract these customers in the first place. Because the spread between the prices charged to new and current customers is higher when $n>2$, there is actually more (inefficient) switching when the market is fully competitive.

Consumer heterogeneity and firm learning are explored in Section 5. Specifically, the model of Section 4 is extended to allow for two types of consumers, those who tend to have high switching costs and those who tend to have low ones. Also, it is assumed that firms can track consumer behavior over time and tailor their offers accordingly. In fact, firms in a number of markets, including long distance and credit cards, maintain databases of consumer characteristics and purchase histories that they use for direct marketing purposes (see Rossi, McCulloch, and Allenby, 1996). In the context of the model considered here, subscribers who switch frequently (switchers) are relatively more likely to be low-cost individuals than those who seldom switch (stickers). It is shown that switchers receive better price offers from their current suppliers, while stickers receive better offers to switch. Interestingly, adverse selection cuts both ways in this setting. Low-cost switchers benefit from pooling with high-cost switchers, while high-cost stickers benefit from pooling with low-cost stickers.

Some brief concluding remarks appear in Section 6. All proofs and two technical lemmas have been relegated to the Appendix.

\section{The model}

The consumers. The market contains a continuum of consumers with total mass normalized to one. Each consumer $i \in[0,1]$ is a risk-neutral expected-utility maximizer and has discount factor $\delta \in[0,1]$. There are $T+1<\infty$ periods, $t=0, \ldots, T .^{11}$

${ }^{9}$ Farrell and Shapiro (1988) obtain uniqueness and independence of prices on market shares in an anonymous switching-cost model by considering a stage game in which duopolists set prices sequentially in each period in an alternating fashion. The firm that moves second undercuts its rival and captures the entire market for that period.

${ }^{10}$ A similar result concerning the convergence of market shares is obtained by Beggs and Klemperer (1992) in an infinite-horizon, anonymous, switching-cost model with entry of new consumers. Also see Villas-Boas (1999).

11 The setting studied in the next two sections possesses a unique subgame-perfect equilibrium outcome when $T<\infty$. When $T=\infty$, however, there may also be many folk-theorem-type equilibria. 
In each period, each consumer chooses to subscribe to one of $n>1$ suppliers. These firms produce a homogeneous nondurable good or service for each of their subscribers in each period. Every consumer values one unit of the good or service at $v$ and additional units at zero, where $v$ is large enough that consumers always prefer to subscribe to some firm. ${ }^{12}$

Also, in each period, each consumer learns his current cost of switching suppliers. Specifically, in each period $t$ each consumer $i$ receives an i.i.d. draw $c_{t}^{i} \in[0,1]$ from the distribution $G(c)$ that specifies his current cost of changing suppliers. ${ }^{13}$

The distribution function, $G(c)$, is twice continuously differentiable, and $G(0)=1-G(1)=$ 0 . The density function, $g(c)$, is strictly positive everywhere on $[0,1]$. In addition, the following hazard rate assumptions are maintained throughout. ${ }^{14}$

Assumption 1 (increasing right-tail hazard). $1-G(c)$ is log-concave.

Assumption 2 (increasing left-tail hazard). $G(c)$ is log-concave.

As noted in the Introduction, switching costs represent the time, effort, and other resources an individual must spend in order to change suppliers, e.g., the time and effort required to close one checking account and open a new one or the hassle involved in switching long-distance companies or Internet service providers. Such costs are likely to vary from period to period because of the uncertain demands on an individual's time and other resources. The realization of an individual's switching cost is private nonverifiable information.

The firms. Each firm $j \in\{1, \ldots, n\}$ has identical constant-returns technology with marginal cost normalized to zero. ${ }^{15}$ The firms are risk-neutral expected-profit maximizers and discount according to $\delta$. Each firm knows whether or not a given consumer subscribed to it in the previous period. Thus, in each period $t$, each firm $j$ can price discriminate by offering price $\bar{p}_{t}^{j}$ to consumers who subscribed to it in the previous period and $p^{j}$ to consumers who did not. ${ }^{16}$ Let $s_{t}^{j}$ be the market share of firm $j$ in period $t$ (i.e., a measure $s_{t}^{j}$ of consumers subscribed to firm $j$ in period $t-1)$. Let $p_{t} \in \Re^{2 n}$ denote the vector of period-t prices, $p_{t} \equiv\left(\bar{p}_{t}^{1}, \underline{p}_{t}^{1} ; \ldots ; \bar{p}_{t}^{n}, \underline{p}_{t}^{n}\right)$. Also, denote the vector of market shares by $s_{t} \in S^{n}$, where $S^{n}$ is the $n$-dimensional unit simplex.

The timing. At the beginning of each period $t$, each firm $j$ observes the prices charged in the previous period, $p_{t-1}$, and the vector of current market shares, $s_{t}$, and then sets its prices $\left(\bar{p}_{t}^{j}, \underline{p}_{t}^{j}\right)$. Next, each consumer $i$ observes his current cost of switching, $c_{t}^{i}$, and the current prices, $p_{t}$, and then chooses a supplier.

\section{Duopoly}

A monopolist operating in this setting would simply post a single price of $v$ in each period and extract all the surplus. Things are more interesting, however, when more than one firm serves

12 The model can be adapted to handle more complicated demand specifications at the cost of additional analytic complexity. Assuming identical consumers with unit demands eliminates inefficiency due to quantity distortions and facilitates analysis of the inefficiency created by switching.

${ }^{13}$ A setting with consumer heterogeneity is studied in Section 5, but serial correlation is not considered explicitly. While serial correlation in switching costs is interesting (and probably realistic), the results under such a setting are apt to be qualitatively similar to those of the benchmark model presented here. The main difference under serial correlation is likely to be that the offers made to a consumer by his supplier would rise over time until he found it optimal to switch. For an example of such dynamic cycles in a different (but related) setting, see Kennan (2001).

${ }^{14} \mathrm{~A}$ fairly large class of distributions satisfes Assumptions 1 and 2. Also, Assumption 2 is required only for the duopoly version of the model investigated in the next section.

15 The model can be modified to include a fixed cost, $f>0$, to the firms of making an offer to a potential subscriber. This cost can include both direct marketing costs such as mail and telephone solicitation and any physical cost of initiating a subscription. With a finite horizon, such a cost causes prices to rise over time because the firms have ever-fewer periods over which to amortize $f$. The welfare implications of this cost are ambiguous-each switch creates more social waste but less switching occurs in equilibrium.

${ }^{16}$ In order to study potential asymmetries in initial market shares (e.g., a monopolist facing an entrant), it is assumed that each consumer is attached to a firm in the initial period. The model can, however, easily be altered to handle the case in which consumers are initially unattached. 
the market. It turns out that subscription markets (as modelled here) are fully competitive only if $n>2$. To highlight this point, I investigate the duopoly case in this section and take up the more general case of $n>2$ in the next one.

Lemma 1 identifies the critical level of switching cost under duopoly, and Proposition 1 fully characterizes the equilibrium in this setting.

Lemma 1 (the marginal switcher). Consider the function

$$
\phi(c) \equiv \frac{1-2 G(c)}{g(c)}-c .
$$

(i) There exists a unique switching $\operatorname{cost} c^{*} \in(0,1)$, satisfying $\phi\left(c^{*}\right)=0$, and

(ii) $G\left(c^{*}\right)<1 / 2$.

Before stating Proposition 1 , it is convenient to define

$$
b_{t} \equiv\left(\frac{\left(G\left(c^{*}\right)\right)^{2}}{g\left(c^{*}\right)}\right)\left(\frac{1-\delta^{T+l-t}}{1-\delta}\right) .
$$

Proposition I (duopoly equilibrium). When $n=2$, there is a unique subgame-perfect equilibrium characterized as follows.

Consumers. Each consumer $i$ switches from firm $j$ to $k$ in period $t$ if and only if

$$
\bar{p}_{t}^{j}-\underline{p}_{t}^{k} \geq c_{t}^{i}
$$

Prices. For $t<T(t=T)$, each firm offers its current subscribers $\bar{p}^{*}\left(\bar{p}^{*}+\delta c^{*}\right)$ and offers new subscribers $\underline{p}^{*}\left(\underline{p}^{*}+\delta c^{*}\right)$, where

$$
\bar{p}^{*} \equiv \frac{1-G\left(c^{*}\right)}{g\left(c^{*}\right)}-\delta c^{*}
$$

and

$$
\underline{p}^{*} \equiv \frac{G\left(c^{*}\right)}{g\left(c^{*}\right)}-\delta c^{*}
$$

Market shares. Firm j's market share at date $t$ is

$$
s_{t}^{j}=s_{0}^{j}\left(1-2 G\left(c^{*}\right)\right)^{t}+\frac{1}{2}\left(1-\left(1-2 G\left(c^{*}\right)\right)^{t}\right) .
$$

Profit. The expected discounted profit to firm $j$ at date $t$ deriving from one of its own customers is $\pi_{t}^{+}=c^{*}+b_{t}$, and the expected discounted profit to firm $j$ at date $t$ deriving from one of firm $k$ 's customers is $\pi_{t}^{-}=b_{t}$. Hence, firm $j$ 's overall discounted profit at date $t$ is

$$
\Pi_{t}^{j}\left(s_{t}^{j}\right)=s_{t}^{j} c^{*}+b_{t}
$$

S Sketch of proof. To understand the determination of $c^{*}$ and of the equilibrium prices $\vec{p}^{*}$ and $\underline{p}^{*}$, consider firm $j$ 's problem when making an offer to one of its current customers:

$$
\pi_{t}^{+}=\max _{\left\langle\bar{p}^{j} \in \Re\right\rangle}\left(1-G\left(\bar{p}^{j}-\underline{p}^{*}\right)\right)\left(\bar{p}^{j}+\delta \pi_{t+1}^{+}\right)+G\left(\bar{p}^{j}-\underline{p}^{*}\right) \delta \pi_{t+1}^{-} .
$$

The first term on the right is the probability of retaining the customer times the value of retention, and the second term is the probability of losing him times the corresponding value. The first-order - RAND 2003. 
condition can be written

$$
\frac{1-G\left(\bar{p}^{j}-\underline{p}^{*}\right)}{g\left(\bar{p}^{j}-\underline{p}^{*}\right)}-\bar{p}^{j}=\delta\left(\pi_{t+1}^{+}-\pi_{t+1}^{-}\right) .
$$

The right side of this expression is the difference in next period's profit between retaining and losing the customer. The left side of (6) is decreasing by Assumption 1. Hence, there is a unique solution, $\bar{p}^{j}=\bar{p}^{*}$.

Next, consider firm $j$ 's problem when making an offer to one of $k$ 's current customers:

$$
\pi_{t}^{-}=\max _{\left\langle\underline{p}^{j} \in \Re\right\rangle} G\left(\bar{p}^{*}-\underline{p}^{j}\right)\left(\underline{p}^{j}+\delta \pi_{t+1}^{+}\right)+\left(1-G\left(\bar{p}^{*}-\underline{p}^{j}\right)\right) \delta \pi_{t+1}^{-} .
$$

The first term on the right is the probability of attracting the customer times the value of obtaining his business, and the second term is the probability that the customer does not leave firm $k$ times the corresponding value to $j$. The first-order condition can be written

$$
\frac{G\left(\bar{p}^{*}-\underline{p}^{j}\right)}{g\left(\bar{p}^{*}-\underline{p}^{j}\right)}-\underline{p}^{j}=\delta\left(\pi_{t+1}^{+}-\pi_{t+1}^{-}\right) .
$$

The left side of (7) is decreasing by Assumption 2. Hence, there is a unique solution, $p^{j}=p^{*}$.

Next, note that the right side of (6) is the same as the right side of (7). Specifically, the net value of retaining a customer is the same as the net value of attracting a new one. In fact, it can be shown that the net value of retaining or attracting a customer is constant over time (and equal to the rent $c^{*}$ that can be extracted from a subscriber). Equating the left side of (6) to the left side of (7) then yields the condition $\phi\left(c^{*}\right)=0$ that implicitly defines the time-invariant marginal type, $c^{*}$. Next, using the definition of $c^{*}$, it can be shown that $\pi_{t}^{+}=c^{*}+b_{t}$ and $\pi_{t}^{-}=b_{t}$. Substituting these into (6) and (7) yields the definitions of $\bar{p}^{*}$ and $\underline{p}^{*}$ respectively. (Consult the Appendix for the complete proof.)

Discussion. Lemma 1 and Proposition 1 indicate that there exists a unique switchingcost level, $c^{*}$, such that any consumer $i$ with $c_{t}^{i}<c^{*}$ switches suppliers in period $t$. In other words, subscribers follow a (myopic) reservation-cost switching rule in equilibrium. Hence, $G\left(c^{*}\right)$ consumers switch suppliers every period. Part (ii) of Lemma 1 indicates that this is less than half the consumers in the market. Equivalently, once a consumer is attached to a firm, the expected duration of his subscription is $1 / G\left(c^{*}\right)>2$ periods. For instance, if $G(c)=c$ (the uniform distribution), then $\phi(c)=1-3 c$ and $c^{*}=1 / 3$. In other words, one-third of the consumers switch suppliers each period and the expected duration of a subscription is three periods.

It is, of course, inefficient for consumers to switch suppliers. The equilibrium level of deadweight loss created by supplier surfing in each period is

$$
\int_{0}^{c^{*}} c g(c) d c
$$

which can be a significant fraction of social surplus depending on the value of $v$.

Given that switching is costly and inefficient, why does it occur? The answer is that the realization of a consumer's switching cost is private unverifiable information. Hence, to obtain a price lower than $\bar{p}^{*}$, it is necessary for a consumer to credibly reveal his switching-cost realization by actually changing suppliers. ${ }^{17}$

${ }^{17}$ In fact, the act of contacting his current supplier to negotiate a price concession could serve as a signal that a consumer has a low opportunity cost of time, i.e., that he is likely to switch if he does not receive an adequate concession. It is relatively straightforward to extend the model to allow for this. 
Next, consider the firms. First, equilibrium prices do not depend on market shares. Hence, whether the industry starts as a symmetric duopoly, $s_{0}^{j}=1 / 2$, or as a monopoly contested by an entrant, $s_{0}^{j}=1-s_{0}^{k}=1$, both firms set the same prices in every period. The intuition is straightforward. In a standard switching-cost model with anonymous consumers (e.g., Klemperer, 1987a), firms must set the same price to new and old customers alike. Hence, one price serves two functions: it attracts new customers and simultaneously milks old ones. A firm with a small market share will, therefore, price more aggressively than one with a large base of customers to milk. In subscription markets, by contrast, firms can distinguish between new and old customers. They, therefore, attempt to attract new customers with a low price and milk their old customers with a high one. Since no tradeoff between attracting new customers and milking old ones is necessary, prices are independent of market shares.

Another feature of the equilibrium is that prices in periods 0 through $T-1$ are constant and depend negatively on $\delta$. The intuition here is also straightforward. Each firm is interested in increasing its customer base. Its incentive for setting a low value of $\bar{p}_{t}^{j}$ is to hold on to its current subscribers, and its incentive for setting a low value of $p^{j}$ is to lure subscribers away from its rival. As $\delta$ declines, the net value of retaining and/or attracting a customer, $\delta c^{*}$, shrinks relative to the value of current profit, weakening the incentives to set low prices. Prices in the final period jump up by $\delta c^{*}$ because there is obviously no return to building market share at this point.

Continuing with the uniform-distribution example, (2) and (3) give $\bar{p}^{*}=(2-\delta) / 3$ and $p^{*}=(1-\delta) / 3$. As the firms become more patient, the equilibrium introductory price in periods $t<T$ tends to the marginal cost of zero. In general, as $\delta$ approaches one, $p^{*}$ goes to $\left(3 G\left(c^{*}\right)-1\right) / g\left(c^{*}\right)$, which is negative (i.e., below marginal cost) if $G\left(c^{*}\right)<1 / 3$.

Next, consider the evolution of market shares given in (4). At any date $t$, a firm's market share is a convex combination of its initial market share and $1 / 2$. Moreover, as $t$ grows, weight is shifted away from initial market shares onto $1 / 2$. In other words, the industry converges to symmetric duopoly in the long run. The rate of convergence depends on the mass of consumers who switch in each period. For instance, as $G\left(c^{*}\right)$ tends to the limiting case of $1 / 2$, expression (4) indicates that convergence to symmetry occurs after only one round of switching. Conversely, in the limit as $G\left(c^{*}\right)$ approaches zero, no consumers switch, and initial market shares persist indefinitely. This is easily understood. In equilibrium, each firm loses a fixed fraction, $G\left(c^{*}\right)$, of its subscribers to its rival in each period. Hence, the firm with the larger customer base loses absolutely more subscribers than it lures away.

Finally, consider the expression for profit given in (5). There are two points worth mentioning. First, equilibrium profit is increasing in market share, and the marginal value of an additional subscriber is $c^{*}$. Second (and more important), the present value of duopoly profit is positive even for an entrant that starts with no subscribers. The reason for this is that when there are only two firms in the industry, switching costs significantly soften price competition. A consumer contemplating a switch has only two options: stay with his current supplier and pay its (high) standard price or switch to the other firm and pay its (low) introductory price and incur the cost of switching. Hence, one firm's low price competes with the other's high price and vice versa. In the next section I show that this "soft" competition is peculiar to a duopoly market structure.

\section{Full competition}

When there are more than two firms in the industry, a subscriber who leaves his current supplier can switch to one of at least two others. Resolving indifference, therefore, requires a tie-breaking rule.

Assumption 3 (symmetric tie breaking). A consumer who is indifferent about switching to one of several firms selects among them randomly with equal probability.

It is also helpful to define the following notation:

$$
\underline{p}_{t}^{\min } \equiv \min \left\{\underline{p}_{t}^{1}, \ldots, \underline{p}_{t}^{n}\right\}
$$


and

$$
\underline{p}_{t}^{j^{\prime}} \equiv \min \left\{\left\{\underline{p}_{t}^{1}, \ldots, \underline{p}_{t}^{n}\right\} \backslash\left\{\underline{p}_{t}^{j}\right\}\right\}
$$

In words, $\underline{p}_{t}^{\min }$ is the lowest introductory price offered by any firm in period $t$, and $\underline{p}_{t}^{j^{\prime}}$ is the lowest introductory price offered by a firm other than $j$.

Lemma 2 identifies the critical level of switching cost in this setting, and Proposition 2 gives a full characterization of all equilibria.

Lemma 2 (the marginal switcher). Consider the function

$$
\gamma(c) \equiv \frac{1-G(c)}{g(c)}-c
$$

There exists a unique switching cost $c^{* *} \in(0,1)$, satisfying $\gamma\left(c^{* *}\right)=0$.

Proposition 2 (competitive equilibrium). When $n>2$, subgame-perfect equilibrium payoffs are unique, and equilibrium behavior is characterized as follows. only if

Consumers. Each consumer $i$ switches from firm $j$ to a firm charging $\underline{p}_{t}^{j^{\prime}}$ in period $t$ if and

$$
\bar{p}_{t}^{j}-\underline{p}_{t}^{j^{\prime}} \geq c_{t}^{i}
$$

Prices. In period $t<T(t=T)$, each firm offers its current subscribers $\bar{p}^{* *}\left(c^{* *}\right)$, where

$$
\bar{p}^{* *} \equiv c^{* *}-\delta\left(1-G\left(c^{* *}\right)\right) c^{* *}
$$

In period $t<T(t=T)$, at least three firms make introductory offers of $\underline{p}_{t}^{\min }=\underline{p}^{* *}(0)$, where

$$
\underline{p}^{* *} \equiv-\delta\left(1-G\left(c^{* *}\right)\right) c^{* *}
$$

Profit. The expected discounted profit to firm $j$ at date $t$ deriving from one of its own customers is $\pi^{+}=\left(1-G\left(c^{* *}\right)\right) c^{* *}$ and the expected discounted profit to firm $j$ at date $t$ deriving from one of its rival's customers is $\pi^{-}=0$. Hence, firm $j$ 's overall discounted profit at date $t$ is

$$
\Pi_{t}^{j}\left(s_{l}^{j}\right)=s_{t}^{j}\left(1-G\left(c^{* *}\right)\right) c^{* *}
$$

Sketch of proof. To understand the determination of $c^{* *}$ and of the equilibrium prices $\bar{p}^{* *}$ and $\underline{p}^{* *}$, consider firm $j$ 's problem when making an offer to one of its current customers:

$$
\pi^{+}=\max _{\left\langle\bar{p}^{j} \in \Re\right)}\left(1-G\left(\bar{p}^{j}-\underline{p}^{* *}\right)\right)\left(\bar{p}^{j}+\delta \pi^{+}\right)+G\left(\bar{p}^{j}-\underline{p}^{* *}\right) \delta \pi^{-} .
$$

The first term on the right is the probability of retaining the customer times the value of retention, and the second term is the probability of losing him times the corresponding value. The first-order condition can be written

$$
\frac{1-G\left(\bar{p}^{j}-\underline{p}^{* *}\right)}{g\left(\bar{p}^{j}-\underline{p}^{* *}\right)}-\bar{p}^{j}=\delta\left(\pi^{+}-\pi^{-}\right) .
$$

The right side of this expression is the difference in next period's profit between retaining and losing the customer. The left side of (11) is decreasing by Assumption 1. Hence, there is a unique solution, $\bar{p}^{j}=\bar{p}^{* *}$. 
Next, consider firm $j$ 's problem when making an offer to one of its rival's current customers. Unlike the duopoly case, $j$ will face competition for this potential switcher from another firm (say $k$ ). Specifically, in equilibrium $j$ and $k$ will bid away all the expected profit from attracting the new customer,

$$
\pi^{-}=G\left(\bar{p}^{* *}-\underline{p}^{j}\right)\left(\underline{p}^{j}+\delta \pi^{+}\right)+\left(1-G\left(\bar{p}^{* *}-\underline{p}^{j}\right)\right) \delta \pi^{-}=0 .
$$

This implies $\underline{p}^{j}=-\delta \pi^{+}$. Substituting this and $\pi^{-}=0$ into (11) yields $\gamma\left(c^{* *}\right)=0$. This then yields

$$
\pi^{+}=\left(1-G\left(c^{* *}\right)\right)\left(\bar{p}^{* *}+\delta \pi^{+}\right)=\left(1-G\left(c^{* *}\right)\right)\left(\bar{p}^{* *}-\underline{p}^{* *}\right)=\left(1-G\left(c^{* *}\right)\right) c^{* *} .
$$

The definition of $\bar{p}^{* *}$ then follows directly. (Consult the Appendix for the complete proof.)

Discussion. While there is not a unique equilibrium when $n>2$, all of the equilibria are payoff equivalent. The equilibrium outcomes resemble the duopoly outcome in several ways, but there are some important differences.

First, although consumers use a reservation-cost rule in both settings, they switch more when $n>2$. To see this, note that $\phi(c)<\gamma(c)$; the fact that both functions are monotone decreasing then implies $c^{*}<c^{* *}$. For instance, under the uniform distribution, $G\left(c^{*}\right)=1 / 3$, while $G\left(c^{* *}\right)=1 / 2$.

The intuition for why $c^{*}<c^{* *}$ is simple. Under duopoly, competition is soft in the sense that the only substitute for switching to a new supplier is to remain with one's current firm. In other words, there is no competition for switchers. When $n>2$, by contrast, at least two firms will vie for the business of any switcher, competing away all the expected profit from attracting him. This aggressive competition for switchers creates a large gap between the price firms set for old and new customers, which induces more switching by consumers than occurs under duopoly.

Note that $c^{*}<c^{* *}$ implies that deadweight loss is actually higher when $n>2$ because more consumers switch suppliers. In fact, deadweight loss would be minimized (and equal to zero) in this model under monopoly. Specifically, no switching would be possible, and the monopolist would, therefore, extract all the social surplus by setting $\bar{p}_{t}=p=v$. (This obviously depends on identical consumers with unit demands.) Although more switching occurs when $n>2$ than when $n=2$, it can be shown that aggregate consumer surplus is always higher and aggregate producer surplus is always lower in the more competitive environment.

Next, consider prices. To begin with, while all firms offer the same price, $\bar{p}^{* *}$, to their current subscribers, equilibrium requires only three firms to offer $p^{* *}$ to switchers. The remaining $n-3$ firms may offer higher introductory prices, although they will not attract new customers. In fact, attracting new subscribers at price $p^{* *}$ generates zero expected profit.

Recall that in a static Bertrand game, only two firms must price at marginal cost in equilibrium. The dynamic Bertrand setting considered here requires at least three firms to offer zero-profit introductory prices in equilibrium because at least two firms must compete for any consumer willing to leave his current supplier. Also, $p^{* *}<0$. In other words, introductory prices are always below marginal cost when $t<T$ and $n>\overline{2}$. This occurs because firms use the introductory price to bid away the expected profit associated with a new subscriber. As in the duopoly setting, prices jump up in the last period by the present value of attracting a new subscriber, which (in this case) is $\delta\left(1-G\left(c^{* *}\right)\right) c^{* *}$.

Next, consider the expression for profit given in $(10)$. First, $\Pi_{t}^{j}(0)=0$. In other words, unlike the duopoly case, an entrant makes a discounted profit of zero. More generally, a firm's equilibrium payoff is proportional to its market share. Specifically, it makes expected discounted profit of $\left(1-G\left(c^{* *}\right)\right) c^{* *}$ from each of its $s_{t}^{j}$ current subscribers. Indeed, $\Pi_{t}^{j}\left(s_{t}^{j}\right)$ should not be regarded as economic profit. Rather, it is the present value of the quasi-rent stream associated with its customer base, which requires substantial upfront investment to build.

There is a simple point here that is, nevertheless, worth emphasizing. Consider, for example, the general-purpose credit card market. Some studies—most notably Ausubel (1991)—claim to ( RAND 2003 
have discovered significant economic profits in this industry. In terms of the model presented here, the fact that a firm charges its current subscribers $\bar{p}^{* *}>0$ implies that it earns positive economic rent, but not positive economic profit. A firm's current customer base is an asset that requires significant upfront investment to secure. In other words, assessing the "profitability" of a subscription market necessitates a careful accounting of the resources needed to attract a new subscriber. In the current model, the only such resource is the signing bonus $\left(\underline{p}^{* *}<0\right)$ paid to new subscribers. While such bonuses are common in subscription markets, firms often incur other marketing expenses in attracting new subscribers. ${ }^{18}$

$\square$ Market shares. When $n>3$, it is not generally possible to track the evolution of equilibrium market shares. Firms that make introductory offers of $p^{* *}$ attract new subscribers, but equilibrium requires only three of the $n$ firms to set this price in any period. This implies that no firm can maintain a market share strictly greater than $1 / 3$, but it implies little else. If, however, attention is restricted to the unique full-participation equilibrium in which all $n$ firms make introductory offers of $\underline{p}^{* *}$ in every period, then it is possible to track the evolution of market shares. The industry dynamics are most reasonable under the following assumption (which is automatically satisfied for large-enough $n) .{ }^{19}$

Assumption 4 (bounded switching). The mass of consumers who switch in a given period is bounded as follows:

$$
G\left(c^{* *}\right) \leq \frac{n-1}{n} .
$$

Proposition 3. In the unique full-participation equilibrium, firm $j$ 's market share at date $t$ is

$$
s_{t}^{j}=s_{0}^{j}\left(1-\frac{n}{n-1} G\left(c^{* *}\right)\right)^{t}+\frac{1}{n}\left(1-\left(1-\frac{n}{n-1} G\left(c^{* *}\right)\right)^{t}\right) \text {. }
$$

The intuition here is similar to that of the duopoly case. In period $t$, firm $j$ loses $G\left(c^{* *}\right) s_{t}^{j}$ current subscribers and attracts $G\left(c^{* *}\right)\left(1-s_{t}^{j}\right) /(n-1)$ new ones. Thus, a firm loses more subscribers than it attracts if and only if $s_{t}^{j}>1 / n$, which implies convergence to symmetry in the long run.

Optimal sales mechanisms. Before moving to the next section, it is instructive to relate the current setting to other models of selling under asymmetric information. In particular, note that $c^{* *}$ maximizes $(1-G(c)) c$. This is no accident. It occurs because each firm tries to extract surplus from its subscribers in each period by making them a take-it-or-leave-it offer. A given subscriber $i$ is willing to accept an offer in period $t$ with a discounted expected cost to him of $c$ with probability $(1-G(c))$. Specifically, if $c_{t}^{i}<c$, then the consumer will switch and obtain an offer with a discounted expected cost to him of zero. Note that $c^{* *}$ is the price that a seller would set if she faced a single buyer whose valuation for her good was distributed according to $G(\cdot)$. Equivalently, it is the optimal reserve price in an auction where bidders' valuations are i.i.d. draws from $G(\cdot)$ (McAfee and McMillan (1987)). There are, however, two noteworthy differences. First, in the current setting, the expected surplus a firm earns from each of its subscribers is associated with a stream of payments rather than a one-shot sale. Second, in the current setting, market competition gives rise to an endogenous participation constraint for consumers and zero economic profit for firms. In other words, the setting analyzed here can be interpreted as a dynamic version of monopolistic competition where the gross profit deriving from a new subscriber is offset exactly by the upfront cost of attracting him.

${ }^{18}$ Besides the cost of teaser rates, the advertising and mailing costs associated with attracting a new credit card subscriber are reportedly between $\$ 70$ and $\$ 90$.

${ }^{19}$ If Assumption 4 is violated, each firm's market share oscillates around $1 / n$ from period to period but still converges.

(- RAND 2003. 


\section{Consumer heterogeneity and firm learning}

- To analyze issues involving consumer heterogeneity, the model of the previous section is extended here to allow for two types of subscribers, those who tend to have high switching-cost realizations, $\theta=H$, and those who tend to have low ones, $\theta=L .{ }^{20}$ In particular, $\alpha$ of the consumers receive i.i.d. switching-cost draws in each period from the distribution $G^{H}(c)$, while $1-\alpha$ of them receive draws from $G^{L}(c)$. For ease of exposition, I study a two-period horizon $(t=0,1)$ with $n>2$ firms. Also, each firm $j$ begins with $\alpha s_{0}^{j}$ type- $H$ subscribers and $(1-\alpha) s_{0}^{j}$ type- $L$ ones. The distributions $G^{H}(c)$ and $G^{L}(c)$ satisfy the following two conditions.

Assumption 5 (increasing hazard). For all $\beta \in[0,1]$, the function $1-\left(\beta G^{H}(c)+(1-\beta) G^{L}(c)\right)$ is $\log$-concave in $c$.

Assumption 6 (hazard ranking). For all $c \in(0,1), \gamma^{H}(c)>\gamma^{L}(c)$, where

$$
\gamma^{\theta}(c)=\frac{1-G^{\theta}(c)}{g^{\theta}(c)}-c
$$

Assumption 5 extends the log-concavity of Assumption 1 to the mixed distribution $\beta G^{H}(c)+(1-\beta) G^{L}(c)$. This ensures sufficiency of first-order conditions.

Assumption 6 ranks the two distributions with respect to hazard functions. An implication of this ranking is $G^{H}(c)<G^{L}(c)$ for $0<c<1$; i.e., $G^{H}(\cdot)$ strictly stochastically dominates $G^{L}(\cdot)$ in the first-order sense. Hence, type- $H$ consumers have higher switching-cost realizations on average than type- $L$ ones. ${ }^{21}$

To begin the analysis in this setting, consider a situation in which the firms can observe a consumer's type, $\theta^{i}$, but not his switching-cost realization, $c_{t}^{i}$. The results of the previous section extend naturally to this environment. In particular, define $c^{\theta}$ implicitly by $\gamma^{\theta}\left(c^{\theta}\right)=0$. Then, Proposition 2 can be applied separately to each class of subscribers. Assumption 6 implies directly that $c^{H}>c^{L}$. Also, it is straightforward to verify that $\left(1-G^{H}\left(c^{H}\right)\right) c^{H}>\left(1-G^{L}\left(c^{L}\right)\right) c^{L} .^{22}$ In other words, a firm derives more discounted expected profit from a type- $H$ subscriber than from a type- $L$ one. This implies directly that type- $H$ subscribers receive lower first-period introductory offers,

$$
\underline{p}_{0}^{H}=-\delta\left(1-G^{H}\left(c^{H}\right)\right) c^{H}<-\delta\left(1-G^{L}\left(c^{L}\right)\right) c^{L}=\underline{p}_{0}^{L} .
$$

Also, type- $H$ subscribers receive worse offers than type- $L$ subscribers from their suppliers in the last period,

$$
\bar{p}_{1}^{H}=c^{H}>c^{L}=\bar{p}_{1}^{L} .
$$

Now, consider the somewhat more realistic setting in which firms cannot observe a consumer's type but can observe his switching behavior. The object of analysis in this setting is a perfect Bayesian equilibrium with neutral beliefs.

Assumption 7 (neutral beliefs). Firms' beliefs off the equilibrium path regarding a given consumer's type conform to the prior, $\alpha$.

This assumption facilitates learning in equilibrium. In particular, Assumption 7 rules out pooling equilibria in which different types of consumers are induced to take the same first-period action by strong beliefs off the equilibrium path.

Now, begin the analysis by considering period one (the final period). Standard Bertrand-style

${ }^{20}$ It is easy but messy to extend the analysis to more than two types of subscribers.

${ }^{21}$ While Assumption 6 implies first-order stochastic dominance (see Ross (1983)), the converse does not hold. Assumption 6 is analogous to assuming a ranking over marginal revenue functions that implies a ranking over the associated total revenue functions.

${ }^{22}$ To see this, observe that stochastic dominance implies $\left(1-G^{H}\left(c^{L}\right)\right) c^{L} \geq\left(1-G^{L}\left(c^{L}\right)\right) c^{L}$. However, Assumption 1 implies that $c^{H}$ is the unique maximizer of $\left(1-G^{H}(c)\right) c$.

(c) RAND 2003. 
arguments reveal that in any perfect-Bayesian equilibrium, at least three firms offer $\underline{p}_{1}=0$ to any switcher and no firm offers a lower price. Now, consider a firm with a positive measure of subscribers who all faced the same prices in period zero and who all exhibited the same switching behavior. Let $\beta$ denote the firm's belief that any one of these subscribers is type $H$. Then, its pricing problem regarding these consumers can be written (in per-capita terms) as

$$
\pi_{1}(\beta)=\max _{\left\langle\bar{p}_{1} \in \Re\right\rangle}\left(\beta\left(1-G^{H}\left(\bar{p}_{1}\right)\right)+(1-\beta)\left(1-G^{L}\left(\bar{p}_{1}\right)\right)\right) \bar{p}_{1} .
$$

The first-order condition for this problem can be written

$$
\beta g^{H}\left(\bar{p}_{1}\right) \gamma^{H}\left(\bar{p}_{1}\right)+(1-\beta) g^{L}\left(\bar{p}_{1}\right) \gamma^{L}\left(\bar{p}_{1}\right)=0 \text {. }
$$

This implicitly defines the pricing function $\bar{p}_{1}(\beta)$.

Lemma 3. The function $\bar{p}_{1}(\beta)$ is continuous, increasing, and satisfies $\bar{p}_{1}(0)=c^{L}$ and $\bar{p}_{1}(1)=c^{H}$.

This lemma characterizes equilibrium behavior in the final period as a function of beliefs. Specifically, a firm with a mass of subscribers that it believes to be type $H$ with probability $\beta$ offers them price $\bar{p}_{1}(\beta)$. Any of these subscribers with switching-cost realizations greater than $\bar{p}_{1}(\beta)$ accept this offer, while the others switch to a firm offering $\underline{p}_{1}=0$. This means that the expected utility in the final period for a type- $\theta$ consumer (before he knows his switching cost) is

$$
U_{1}^{\theta}(\beta)=v-\int_{0}^{\bar{p}_{1}(\beta)} c g^{\theta}(c) d c-\left(1-G^{\theta}\left(\bar{p}_{1}(\beta)\right)\right) \bar{p}_{1}(\beta)
$$

Integration by parts renders this as

$$
U_{1}^{\theta}(\beta)=v-\int_{0}^{\bar{p}_{1}(\beta)}\left(1-G^{\theta}(c)\right) d c
$$

Stochastic dominance implies that type- $L$ consumers have higher expected utility than type $H$-ones. For $0<\beta<1$, however, the solution involves pooling. This means that a type$L(H)$ subscriber is worse off (better off) than if his type were directly observable because $\bar{p}_{1}^{L}<\bar{p}_{1}(\beta)<\bar{p}_{1}^{H}$. Also, the fact that $\bar{p}_{1}(\beta)$ is increasing implies that $U_{1}^{\theta}(\beta)$ is decreasing. In other words, a subscriber of either type would like his current supplier to believe that he is most likely type $L$ and that it should, therefore, extend him a favorable offer. This raises the question as to how beliefs are formed in equilibrium.

Lemma Al in the Appendix shows that the optimal date-zero strategy for a type- $\theta$ subscriber is to employ a reservation-cost rule under which he changes suppliers if and only if his switching cost is less than some cut-off value $K^{\theta}\left(\bar{p}_{0}-\underline{p}_{0}\right)$. Letting $\beta^{Y}$ denote beliefs about a switcher and $\beta^{N}$ denote beliefs about a sticker and letting $x=\bar{p}_{0}-\underline{p}_{0}$, equilibrium beliefs can be written

$$
\beta^{Y}\left(K^{H}(x), K^{L}(x)\right)=\frac{\alpha G^{H}\left(K^{H}(x)\right)}{\alpha G^{H}\left(K^{H}(x)\right)+(1-\alpha) G^{L}\left(K^{L}(x)\right)}
$$

and

$$
\beta^{N}\left(K^{H}(x), K^{L}(x)\right)=\frac{\alpha\left(1-G^{H}\left(K^{H}(x)\right)\right)}{\alpha\left(1-G^{H}\left(K^{H}(x)\right)\right)+(1-\alpha)\left(1-G^{L}\left(K^{L}(x)\right)\right)} .
$$

Next, to determine the cutoff functions, $K^{H}(x)$ and $K^{L}(x)$, note that if $x \in(0,1)$, then consumer $i$ must be indifferent about changing suppliers in period zero if $c_{0}^{i}=K^{\theta^{i}}(x)$. This implies that the cutoff functions must satisfy 


$$
\begin{aligned}
& v-\bar{p}_{0}+\delta U_{1}^{\theta}\left(\beta^{N}\left(K^{H}(x), K^{L}(x)\right)\right) \\
& \quad=v-\underline{p}_{0}-K^{\theta}(x)+\delta U_{1}^{\theta}\left(\beta^{Y}\left(K^{H}(x), K^{L}(x)\right)\right), \quad \theta \in\{H, L\} x \in(0,1) .
\end{aligned}
$$

Substituting from (14) and rearranging terms gives

$$
K^{\theta}(x)=x+\delta \int_{\bar{p}_{1}\left(\beta^{Y}\left(K^{H}(x), K^{L}(x)\right)\right)}^{\bar{p}_{1}\left(\beta^{N}\left(K^{H}(x), K^{L}(x)\right)\right)}\left(1-G^{\theta}(c)\right) d c, \quad \theta \in\{H, L\} x \in(0,1) .
$$

If $x \geq 1(x \leq 0)$, then all (no) subscribers switch; i.e., $K^{H}(x)=K^{L}(x)=1\left(K^{H}(x)=K^{L}(x)=0\right)$.

Lemma $A 2$ in the Appendix shows that if a solution to (15) exists, then it satisfies $G^{H}\left(K^{H}(x)\right)<G^{L}\left(K^{L}(x)\right)$ for $x \in(0,1)$. This implies that a sticker is relatively more likely to be type $H$ and a switcher is relatively more likely to be type $L$; i.e., $\beta^{Y}<\alpha<\beta^{N}$. Hence, Lemma 3 implies that switchers receive better offers than do stickers from their suppliers in period one, $\bar{p}_{1}\left(\beta^{Y}\right)<\bar{p}_{1}\left(\beta^{N}\right)$. Finally, for any point $\left(k^{H}, k^{L}\right) \in[0,1]^{2}$, define

$$
Q^{\theta}\left(k^{H}, k^{L}\right) \equiv \int_{\bar{p}_{1}\left(\beta^{Y}\left(k^{H}, k^{L}\right)\right)}^{\bar{p}_{1}\left(\beta^{N}\left(k^{H}, k^{L}\right)\right)}\left(1-G^{\theta}(c)\right) d c, \quad \theta \in\{H, L\}
$$

and let $Q_{\theta^{\prime}}^{\theta}$ denote the partial derivative of $Q^{\theta}$ with respect to $k^{\theta^{\prime}}$. With all this in hand, it is now possible to state the main result of this section.

Proposition 4 (equilibrium with learning). If $\delta Q_{L}^{L}<1$, then a unique monotonic solution to (15) exists, and there is a perfect Bayesian equilibrium with neutral beliefs characterized by Lemma 3 and the following.

Consumers. Let $x \equiv \bar{p}_{0}^{j}-\underline{p}_{0}^{j^{\prime}}$. Then, each consumer $i$ switches from firm $j$ to a firm charging $\underline{p}_{0}^{j^{\prime}}$ in period zero if and only if $c_{0}^{i} \leq K^{\theta^{i}}(x)$.

Beliefs. Beliefs on the equilibrium path are given by $\beta^{Y}\left(K^{H}(x), K^{L}(x)\right)$ and $\beta^{N}\left(K^{H}(x), K^{L}(x)\right)$.

Prices. In period zero, each firm offers its current subscribers $\bar{p}_{0}^{\dagger}$, and at least three firms offer switchers $\underline{p}_{0}^{\min }=\underline{p}_{0}^{\dagger}$, where

$$
\begin{aligned}
& \bar{p}_{0}^{\dagger} \equiv \underset{\left\langle\bar{p}_{0} \in \Re\right\rangle}{\operatorname{argmax}}\left(1-\alpha G^{H}\left(K^{H}\left(\bar{p}_{0}-\underline{p}_{0}^{\dagger}\right)\right)-(1-\alpha) G^{L}\left(K^{L}\left(\bar{p}_{0}-\underline{p}_{0}^{\dagger}\right)\right)\right) \\
& \times\left(\bar{p}_{0}+\delta \pi_{1}\left(\beta^{N}\left(K^{H}\left(\bar{p}_{0}-\underline{p}_{0}^{\dagger}\right), K^{L}\left(\bar{p}_{0}-\underline{p}_{0}^{\dagger}\right)\right)\right)\right)
\end{aligned}
$$

and

$$
\underline{p}_{0}^{\dagger} \equiv \min \left\{\underline{p}_{0} \in \Re^{-} \mid \underline{p}_{0}+\delta \pi_{1}\left(\beta^{Y}\left(K^{H}\left(\bar{p}_{0}^{\dagger}-\underline{p}_{0}\right), K^{L}\left(\bar{p}_{0}^{\dagger}-\underline{p}_{0}\right)\right)\right)=0\right\}
$$

$\square \quad$ Discussion. The equilibrium characterized in Proposition 5 exhibits imperfect screening. ${ }^{23}$ Specifically, firms use a consumer's switching behavior to update their beliefs about his type, $\theta=H$ or $\theta=L$. Not all switchers are type $L$ and not all stickers are type $H$, however. In particular, $\alpha G^{H}\left(K^{H}\left(x_{0}^{\dagger}\right)\right)$ type- $H$ consumers have low enough date-zero switching-cost realizations to justify changing suppliers, while $(1-\alpha)\left(1-G^{L}\left(K^{L}\left(x_{0}^{\dagger}\right)\right)\right)$ type- $L$ consumers have switching costs that are too high to warrant changing. Thus, subscribers are screened only imperfectly.

Next, consider the consumers. Each subscriber knows that he will receive a better offer from his supplier in period one if he switches in period zero, and this gives him additional incentives to

${ }^{23}$ For another recent example of screening in the presence of noise, see Jeitschko and Mirman (2002). (c) RAND 2003. 
switch. To see this, note from (15) that $K^{\theta}\left(\bar{p}_{0}-\underline{p}_{0}\right)>\bar{p}_{0}-\underline{p}_{0}$ for $0<\bar{p}_{0}-\underline{p}_{0}<1$. Hence, for $x^{\dagger}<c_{0}^{i} \leq K^{\theta^{i}}\left(x^{\dagger}\right)$, consumer $i$ switches purely for strategic reasons. In other words, he would be better off in the short run staying with his current supplier, but the future benefit from being branded as a switcher makes changing suppliers worthwhile. Indeed, there is a close connection in this context with investing in a reputation. ${ }^{24}$ Each consumer would like his future supplier to believe that he will switch at the drop of a hat, but even a type- $L$ subscriber may find himself in circumstances where investing in a reputation as a switcher is too costly.

Next, as in the previous section, a firm in this setting also earns economic rent from its current base of subscribers, but it must make a zero-profit bid to attract new customers. Specifically, $p_{0}^{\dagger}=-\delta \pi_{1}\left(\beta^{Y}\right)$. This highlights an intriguing point. A consumer who intends to switch would like the firms bidding for his business to believe that he is type $H$. Once he switches, however, he would like his new supplier to believe that he is type $L$. In other words, switchers get better prices when $\beta$ is high, and stickers get better prices when $\beta$ is low. Of course, the act of switching drives $\beta$ down, whereas sticking drives it up.

Note that the unobservability of types generates adverse selection in the market. Specifically, while firms make zero-profit introductory offers, consumers do not share equally in the bounty. In particular, there is an implicit transfer from type- $H$ switchers to type- $L$ ones. To see this, observe that the discounted expected profit from attracting a type- $L$ switcher can be written

$$
\underline{p}_{0}^{\dagger}+\delta\left(1-G^{L}\left(\bar{p}_{1}\left(\beta^{Y}\right)\right)\right) \bar{p}_{1}\left(\beta^{Y}\right)=\delta \beta^{Y}\left(G^{H}\left(\bar{p}_{1}\left(\beta^{Y}\right)\right)-G^{L}\left(\bar{p}_{1}\left(\beta^{Y}\right)\right)\right)
$$

Similarly, the discounted expected profit from attracting a type- $H$ switcher can be written

$$
\underline{p}_{0}^{\dagger}+\delta\left(1-G^{H}\left(\bar{p}_{1}\left(\beta^{Y}\right)\right)\right) \bar{p}_{1}\left(\beta^{Y}\right)=\delta\left(1-\beta^{Y}\right)\left(G^{L}\left(\bar{p}_{1}\left(\beta^{Y}\right)\right)-G^{H}\left(\bar{p}_{1}\left(\beta^{Y}\right)\right)\right)
$$

The first of these expressions is negative and the second one is positive (by stochastic dominance). Hence, a type- $L$ switcher expects to get his subscription below cost, while a type- $H$ switcher expects to pay a premium.

As noted above, the subsidy flows in the reverse direction when considering stickers rather than switchers. Specifically, a type- $H$ sticker pays a lower price than he would if his type were observable, and a type- $L$ sticker pays a correspondingly higher price. Both patterns of subsidization give type- $L$ consumers incentives to switch and type- $H$ consumers incentives to stick. This is precisely what generates dynamic screening.

Finally, some speculation about longer time horizons is in order. If firms could observe consumer switching behavior over many periods, it seems likely that beliefs would become more precise over time. Indeed, after a long enough time, it seems likely that firms would be fairly certain about the type of each consumer in the market. In other words, $\beta_{t}$ would tend to one or zero depending respectively on whether a consumer was type $H$ or $L$. In this case, the offers made by firms and switches made by consumers would converge to the situation described in Proposition 2 except that $G(\cdot)$ would be replaced by $G^{H}(\cdot)$ if $\beta_{t} \rightarrow 1$ and $G^{L}(\cdot)$ if $\beta_{t} \rightarrow 0$. Hence, it seems reasonable to view the analysis of Section 4 as the likely long-run outcome in a market where firms have observed each consumer's behavior for an extended length of time.

\section{Conclusion}

- In this article I have explored the common practice in subscription markets of offering customers enticements to switch suppliers. It was shown that this behavior-based price discrimination is the natural mode of competition in subscription markets when it is not possible to commit to life-long contracts. Consumers respond to introductory offers by switching their

${ }^{24}$ Prendergast and Stole (1995) study a technically related setting in which a manager may "invest" in a reputation as a fast learner.

o RAND 2003. 
subscriptions in periods when they are not too busy. Otherwise, they remain with the same supplier and pay its standard rate. Hence, a firm's base of subscribers is a valuable asset.

When there are only two firms operating in a subscription market, competition is soft and both firms consequently earn strictly positive economic profit. When there are three or more firms in the industry, however, full-fledged price competition kicks in, and each firm earns economic rent on its customer base but zero economic profit. Specifically, each firm offers switchers an introductory price below cost and later recoups this marketing investment from nonswitchers. Somewhat paradoxically, the fully competitive setting can be less efficient than the duopoly setting because the aggressive introductory prices under full competition induce more consumers to switch.

A generalization of the basic model in which some consumers have a higher value of time on average than others and firms can track subscriber behavior was also considered. In this context, consumers were shown to possess a strategic incentive to switch suppliers. Specifically, subscribers who are branded as switchers receive better offers from future suppliers. Also, adverse selection in this setting was shown to be double-sided in the sense that high-cost switchers were hurt by pooling with low-cost switchers and low-cost stickers were hurt by pooling with high-cost stickers.

One of the more intriguing predictions of the model was that (in the absence of mergers or acquisitions) no firm should be able to maintain a dominant position in a subscription market. In this regard, it is interesting to note the shift in market shares in the U.S. long-distance telephone industry between 1984 and 1996 as reported in Pietrucha (1997). Over this time, AT\&T's market share slipped steadily from $89 \%$ to $54 \%$, while the market shares of all other long-distance companies grew: MCI's from $5 \%$ to $18 \%$, Sprint's from $3 \%$ to $9 \%$, and all others' from $4 \%$ to $20 \% .{ }^{25}$

There are many directions in which the analysis presented here could be extended. It would, for instance, be instructive to study the effects of long-term contracts in subscription markets. Also, it would be edifying to investigate firm heterogeneity and more complex demand specifications.

Finally, it should be noted that information technology has made it possible for many firms in standard retail markets to identify consumers and track their purchasing patterns (Bulkeley, 1999; Rossi, McCulloch, and Allenby, 1996). Firms then use this data to formulate nonanonymous direct marketing strategies such as targeted mailings, telephone calls, and point-of-purchase coupons. Hence, subscription markets may not be the only venues in which to find firms offering enticements to their rivals' customers and consumers consequently surfing between suppliers.

\section{Appendix}

- Proofs of all lemmas and propositions presented in the text, as well as the statement and proofs of two technical lemmas used to prove Proposition 4, follow.

Proof of Lemma l. (i) The function $\phi(c)$ is monotone decreasing by Assumptions 1 and 2. Also,

$$
\phi(0)=\frac{1}{g(0)}>0>-\frac{1}{g(1)}-1=\phi(1),
$$

and the claim follows by continuity.

(ii) If $G\left(c^{*}\right)>(1 / 2)$, then $\phi\left(c^{*}\right)<0$ (a contradiction). If $G\left(c^{*}\right)=(1 / 2)$, then $c^{*}=0$ (a contradiction).

Proof of Proposition 1. The claim is proved via backward induction. A consumer with $c$ will switch from firm $j$ to $k$ in the final period if and only if $\bar{p}_{T}^{j}-\underline{p}_{T}^{k} \geq c$. Hence, firm l's problem in period $T$ is

$$
\Pi_{T}^{1}\left(s_{T}^{1}\right)=\max _{\left\langle\left(\bar{p}_{T}^{1}, \underline{p}_{T}^{1}\right) \in \Re^{2}\right\rangle} s_{T}^{1}\left(1-G\left(\bar{p}_{T}^{1}-\underline{p}_{T}^{2}\right)\right) \bar{p}_{T}^{1}+\left(1-s_{T}^{1}\right) G\left(\bar{p}_{T}^{2}-\underline{p}_{T}^{1}\right) \underline{p}_{T}^{1} .
$$

${ }^{25}$ The reason for this shift in market shares is admittedly clouded by the judicial constraints placed on AT\&T's pricing.

(1) RAND 2003. 
It is straightforward to verify that an interior equilibrium must obtain. Hence, when $s_{T}^{1} \in(0,1)$, the first-order necessary conditions can be written

$$
\frac{1-G\left(\bar{p}_{T}^{1}-\underline{p}_{T}^{2}\right)}{g\left(\bar{p}_{T}^{1}-\underline{p}_{T}^{2}\right)}-\bar{p}_{T}^{1}=0
$$

and

$$
\frac{G\left(\bar{p}_{T}^{2}-\underline{p}_{T}^{1}\right)}{g\left(\bar{p}_{T}^{2}-\underline{p}_{T}^{1}\right)}-\underline{p}_{T}^{1}=0
$$

Likewise, the first-order necessary conditions for firm 2 can be written

$$
\frac{1-G\left(\bar{p}_{T}^{2}-\underline{p}_{T}^{1}\right)}{g\left(\bar{p}_{T}^{2}-\underline{p}_{T}^{1}\right)}-\bar{p}_{T}^{2}=0
$$

and

$$
\frac{G\left(\bar{p}_{T}^{1}-\underline{p}_{T}^{2}\right)}{g\left(\bar{p}_{T}^{1}-\underline{p}_{T}^{2}\right)}-\underline{p}_{T}^{2}=0 .
$$

Assumptions 1 and 2 ensure that these conditions are also sufficient for an equilibrium in period $T$. Now, subtract (A4) from (A1) to get $\phi\left(\bar{p}_{T}^{1}-\underline{p}_{T}^{2}\right)=0$ and subtract (A2) from (A3) to get $\phi\left(\bar{p}_{T}^{2}-\underline{p}_{T}^{\mathrm{l}}\right)=0$. Lemma 1 then gives

$$
\bar{p}_{T}^{j}-\underline{p}_{T}^{k}=c^{*}
$$

Substituting this into (Al) through (A4) establishes that $\bar{p}_{T}^{j}=\bar{p}^{*}+\delta c^{*}$ and $\underline{p}_{T}^{j}=\underline{p}^{*}+\delta c^{*}$.

Given equilibrium behavior in period $T$, a consumer with $c$ will switch from firm $j$ to $k$ in period $T-1$ if and only if $\bar{p}_{T-1}^{j}-\underline{p}_{T-1}^{k} \geq c$. Hence, firm l's problem in the penultimate period is

$$
\begin{aligned}
\Pi_{T-1}^{1}\left(s_{T-1}^{1}\right)= & \max _{\left(\left(\bar{p}_{T-1}^{1}, \underline{p}_{T-1}^{1}\right) \in \Re^{2}\right\rangle} s_{T-1}^{1}\left(1-G\left(\bar{p}_{T-1}^{1}-\underline{p}_{T-1}^{2}\right)\right) \bar{p}_{T-1}^{1}+\left(1-s_{T-1}^{1}\right) G\left(\bar{p}_{T-1}^{2}-\underline{p}_{T-1}^{1}\right) \underline{p}_{T-1}^{1} \\
& +\delta \Pi_{T}^{1}\left(\sigma^{1}\left(p_{T-1}, s_{T-1}^{1}\right)\right),
\end{aligned}
$$

where

$$
\sigma^{j}\left(p_{t}, s_{t}^{j}\right) \equiv s_{t}^{j}\left(1-G\left(\bar{p}_{t}^{j}-\underline{p}_{t}^{k}\right)\right)+\left(1-s_{t}^{j}\right) G\left(\bar{p}_{t}^{k}-\underline{p}_{t}^{j}\right), \quad j \in\{1,2\} \backslash\{k\}, t=0,1, \ldots, T-1 .
$$

Note that

$$
\frac{\partial \sigma^{j}}{\partial \bar{p}_{t}^{j}}=-s_{t}^{j} g\left(\bar{p}_{t}^{j}-\underline{p}_{t}^{k}\right)
$$

and

$$
\frac{\partial \sigma^{j}}{\partial \underline{p}_{t}^{j}}=-\left(1-s_{t}^{j}\right) g\left(\bar{p}_{t}^{k}-\underline{p}_{t}^{j}\right)
$$

Hence, when $s_{T-1}^{1} \in(0,1)$, the first-order necessary conditions for firm 1 can be written

$$
\frac{1-G\left(\bar{p}_{T-1}^{1}-\underline{p}_{T-1}^{2}\right)}{g\left(\bar{p}_{T-1}^{1}-\underline{p}_{T-1}^{2}\right)}-\bar{p}_{T-1}^{1}-\delta \frac{d \Pi_{T}^{1}}{d s_{T}^{1}}=0
$$

and

$$
\frac{G\left(\bar{p}_{T-1}^{2}-\underline{p}_{T-1}^{1}\right)}{g\left(\bar{p}_{T-1}^{2}-\underline{p}_{T-1}^{1}\right)}-\underline{p}_{T-1}^{1}-\delta \frac{d \Pi_{T}^{1}}{d s_{T}^{1}}=0 .
$$

Differentiating $\Pi_{T}^{1}$ yields

(c) RAND 2003.

$$
\frac{d \Pi_{T}^{1}}{d s_{T}^{1}}=\left(1-G\left(c^{*}\right)\right)\left(\bar{p}^{*}+\delta c^{*}\right)-G\left(c^{*}\right)\left(\underline{p}^{*}+\delta c^{*}\right)
$$


Now, use (2) and (3) to write

$$
\left(1-G\left(c^{*}\right)\right)\left(\bar{p}^{*}+\delta c^{*}\right)-G\left(c^{*}\right)\left(\underline{p}^{*}+\delta c^{*}\right)=\frac{\left(1-G\left(c^{*}\right)\right)^{2}-\left(G\left(c^{*}\right)\right)^{2}}{g\left(c^{*}\right)}=c^{*} .
$$

Hence, the necessary conditions for firm 1 become

$$
\frac{1-G\left(\bar{p}_{T-1}^{1}-\underline{p}_{T-1}^{2}\right)}{g\left(\bar{p}_{T-1}^{1}-\underline{p}_{T-1}^{2}\right)}-\bar{p}_{T-1}^{1}-\delta c^{*}=0
$$

and

$$
\frac{G\left(\bar{p}_{T-1}^{2}-\underline{p}_{T-1}^{1}\right)}{g\left(\bar{p}_{T-1}^{2}-\underline{p}_{T-1}^{1}\right)}-\underline{p}_{T-1}^{1}-\delta c^{*}=0
$$

In a similar fashion, the necessary conditions for firm 2 can be written

$$
\frac{1-G\left(\bar{p}_{T-1}^{2}-\underline{p}_{T-1}^{1}\right)}{g\left(\bar{p}_{T-1}^{2}-\underline{p}_{T-1}^{1}\right)}-\bar{p}_{T-1}^{2}-\delta c^{*}=0
$$

and

$$
\frac{G\left(\bar{p}_{T-1}^{1}-\underline{p}_{T-1}^{2}\right)}{g\left(\bar{p}_{T-1}^{1}-\underline{p}_{T-1}^{2}\right)}-\underline{p}_{T-1}^{2}-\delta c^{*}=0 .
$$

Once again, Assumptions 1 and 2 guarantee sufficiency. Also, as above, subtracting (A9) from (A6) and (A7) from (A8) and applying Lemma 1 reveals

$$
\bar{p}_{T-1}^{j}-\underline{p}_{T-1}^{k}=c^{*}
$$

Substituting this fact into (A6) through (A9) gives $\bar{p}_{T-1}^{j}=\bar{p}^{*}$ and $\underline{p}_{T-1}^{j}=\underline{p}^{*}$.

Next, assume that $\bar{p}_{t}^{j}=\bar{p}^{*}$ and $\underline{p}_{t}^{j}=\underline{p}^{*}$ for $j \in\{1,2\}$ and $t=\tau+1, \tau+2, \ldots T-1$. In fact, it is notationally convenient (and without loss of generality) to suppose $\tau=0$. Then, given the hypothesized pricing in periods $t=1, \ldots, T$, a consumer with $c$ will switch from firm $j$ to $k$ in period $t$ if and only if $c \leq c^{*}$. This implies the following evolution of market shares:

$$
s_{t+1}^{j}=s_{t}^{j}\left(1-G\left(c^{*}\right)\right)+\left(1-s_{t}^{j}\right) G\left(c^{*}\right)=G\left(c^{*}\right)+s_{t}^{j}\left(1-2 G\left(c^{*}\right)\right), \quad j \in\{1,2\}, \quad t=1, \ldots, T-1 .
$$

Starting with $s_{1}^{j}$ and using part (ii) of Lemma 1 to iterate gives

$$
s_{t}^{j}=\frac{1}{2}+\left(s_{1}^{j}-\frac{1}{2}\right)\left(1-2 G\left(c^{*}\right)\right)^{t-1}, \quad j \in\{1,2\}, \quad t=1, \ldots, T .
$$

In period 1, firm 1's value function must satisfy

$$
\Pi_{1}^{1}\left(s_{1}^{1}\right)=\sum_{t=1}^{T} \delta^{t-1}\left(s_{t}^{1}\left(1-G\left(c^{*}\right)\right) \bar{p}^{*}+\left(1-s_{t}^{1}\right) G\left(c^{*}\right) \underline{p}^{*}\right)+\delta^{T-1}\left(s_{T}^{1}\left(1-G\left(c^{*}\right)\right) \delta c^{*}+\left(1-s_{T}^{1}\right) G\left(c^{*}\right) \delta c^{*}\right) .
$$

Substituting for $s_{t}^{1}$ from the preceding equation and rearranging terms gives

$$
\begin{aligned}
\Pi_{1}^{\prime}\left(s_{1}^{1}\right)= & \frac{1}{2} \frac{\left(\left(1-G\left(c^{*}\right)\right) \bar{p}^{*}+G\left(c^{*}\right) \underline{p}^{*}\right)\left(1-\delta^{T}\right)}{1-\delta}+\delta^{T} \frac{c^{*}}{2} \\
& +\left(s_{1}^{1}-\frac{1}{2}\right)\left(\frac{\left(\left(1-G\left(c^{*}\right)\right) \bar{p}^{*}-G\left(c^{*}\right) \underline{p}^{*}\right)\left(1-\left(\delta\left(1-2 G\left(c^{*}\right)\right)\right)^{T}\right)}{1-\delta\left(1-2 G\left(c^{*}\right)\right)}+c^{*}\left(\delta\left(1-2 G\left(c^{*}\right)\right)\right)^{T}\right) .
\end{aligned}
$$

This yields

$$
\frac{d \Pi_{1}^{1}}{d s_{1}^{1}}=\frac{\left(\left(1-G\left(c^{*}\right)\right) \bar{p}^{*}-G\left(c^{*}\right) \underline{p}^{*}\right)\left(1-\left(\delta\left(1-2 G\left(c^{*}\right)\right)\right)^{T}\right)}{1-\delta\left(1-2 G\left(c^{*}\right)\right)}+\left(\delta\left(1-2 G\left(c^{*}\right)\right)\right)^{T} c^{*}
$$


Now, use (2) and (3) to write

$$
\left(1-G\left(c^{*}\right)\right) \bar{p}^{*}-G\left(c^{*}\right) \underline{p}^{*}=\frac{\left(1-G\left(c^{*}\right)\right)^{2}-\left(G\left(c^{*}\right)\right)^{2}}{g\left(c^{*}\right)}-\delta\left(1-2 G\left(c^{*}\right)\right) c^{*}=c^{*}\left(1-\delta\left(1-2 G\left(c^{*}\right)\right)\right) .
$$

Substitution gives

$$
\frac{d \Pi_{1}^{1}}{d s_{1}^{l}}=c^{*}
$$

Hence, when $s_{0} \in \operatorname{int}\left(S^{2}\right)$, the first-order necessary conditions for firm 1 in period zero can be written

$$
\frac{1-G\left(\bar{p}_{0}^{1}-\underline{p}_{0}^{2}\right)}{g\left(\bar{p}_{0}^{1}-\underline{p}_{0}^{2}\right)}-\bar{p}_{0}^{1}-\delta c^{*}=0
$$

and

$$
\frac{G\left(\bar{p}_{0}^{2}-\underline{p}_{0}^{l}\right)}{g\left(\bar{p}_{0}^{2}-\underline{p}_{0}^{l}\right)}-\underline{p}_{0}^{1}-\delta c^{*}=0 .
$$

In a similar fashion, the first-order necessary conditions for firm 2 can be written

$$
\frac{1-G\left(\bar{p}_{0}^{2}-\underline{p}_{0}^{1}\right)}{g\left(\bar{p}_{0}^{2}-\underline{p}_{0}^{1}\right)}-\bar{p}_{0}^{2}-\delta c^{*}=0
$$

and

$$
\frac{G\left(\bar{p}_{0}^{1}-\underline{p}_{0}^{2}\right)}{g\left(\bar{p}_{0}^{1}-\underline{p}_{0}^{2}\right)}-\underline{p}_{0}^{2}-\delta c^{*}=0 .
$$

Again, Assumptions 1 and 2 ensure sufficiency. Then, performing the same steps as above yields $\bar{p}_{0}^{j}=\bar{p}^{*}$ and $\underline{p}_{0}^{j}=\underline{p}^{*}$. Expression (5) is obtained by recursively substituting (2) and (3) into the value functions.

Q.E.D.

Proof of Lemma 2. The function $\gamma(c)$ is monotone decreasing by Assumption 1. Also,

$$
\gamma(0)=\frac{1}{g(0)}>0>-1=\gamma(1),
$$

and the claim follows by continuity. Q.E.D.

Proof of Proposition 2. The claim is proved in the same fashion as Proposition 1 except that $p^{j}$ is determined by Bertrand competition rather than a first-order condition.

Suppose $s_{T} \in \operatorname{int}\left(S^{n}\right)$. A consumer with $c$ will switch from firm $j$ to one charging $\underline{p}_{T}^{j^{\prime}}$ in the final period if and only if $\bar{p}_{T}^{j}-\underline{p}_{T}^{j^{\prime}} \geq c$. Given this, it is possible to establish some preliminary facts. First, $\underline{p}_{T}^{j} \geq 0$ for $j \in\{1, \ldots, n\}$ because a firm can only lose money by setting a negative introductory price in the last period. Next, $\bar{p}_{T}^{j}>0$. To see this, note that a firm deviating from zero to $\varepsilon \in(0,1)$ earns at least $s_{T}^{j}(1-G(\varepsilon)) \varepsilon>0$. With this fact in hand, it is possible to use the usual Bertrand-style argument to show that in any equilibrium, at least three firms set $\underline{p}_{T}^{\min }=0$. First, it cannot be that $\underline{p}_{T}^{\min } \geq \max \left\{\bar{p}_{T}^{1}, \ldots, \bar{p}_{T}^{n}\right\}$. To see this, assume the contrary. Then, a firm charging $\underline{p}_{T}^{j} \geq \underline{p}_{T}^{\min }$ could increase its profit by $\underline{p} \sum_{k \neq j} s_{T}^{k} G\left(\bar{p}_{T}^{k}-\underline{p}\right)>0$ if it deviated to any $\underline{p}$ satisfying $0<\underline{p}<\min \left\{\bar{p}_{T}^{1}, \ldots, \bar{p}_{T}^{n}\right\}$. Next, $\underline{p}_{T}^{\min }=0$. To see this, assume the contrary. Then, $\underline{p}_{T}^{\min } \leq \max \left\{\bar{p}_{T}^{1}, \ldots, \bar{p}_{T}^{n}\right\}$ and standard arguments imply that at least one firm can always increase its profit by slightly undercutting $\underline{p}_{T}^{\min }$. Finally, note that in any equilibrium, at least three firms charge $\underline{p}_{T}^{\min }=0$. Clearly, it is not an equilibrium for only one firm to charge zero, because it could increase its profit by charging slightly more. To see that it cannot be an equilibrium for two firms to charge zero, suppose to the contrary that $\underline{p}_{T}^{1}=\underline{p}_{T}^{2}=0$, $\underline{p}_{T}^{3}>0$, and $\underline{p}_{T}^{j} \geq \underline{p}_{T}^{3}$ for $j>3$. If firm 1 raised its price to $\underline{p} \in\left(0, \underline{p}_{T}^{3}\right)$, then it would still get any consumers switching from firm 2 and would, thus, make positive profit for $\underline{p}$ small enough.

Hence, in period $T$ each firm $j \in\{1, \ldots, n\}$ solves

$$
\Pi_{T}^{j}\left(s_{T}^{j}\right)=\max _{\left\langle\bar{p}_{T}^{j} \in \Re\right\rangle} s_{T}^{j}\left(1-G\left(\bar{p}_{T}^{j}\right)\right) \bar{p}_{T}^{j}
$$


The necessary first-order conditions can be written

$$
\frac{1-G\left(\bar{p}_{T}^{j}\right)}{g\left(\bar{p}_{T}^{j}\right)}-\bar{p}_{T}^{j}=0, \quad j \in\{1, \ldots, n\}
$$

These conditions are also sufficient by Assumption 1. In addition, applying Lemma 2 yields $\bar{p}_{T}^{j}=c^{* *}$, and this gives

$$
\Pi_{T}^{j}\left(s_{T}^{j}\right)=s_{T}^{j}\left(1-G\left(c^{* *}\right)\right) c^{* *}
$$

Now move back to period $T-1$ and assume $s_{T-1} \in \operatorname{int}\left(S^{n}\right)$. Any consumer who buys from a firm in this period will stay attached to it in period $T$ and pay $c^{* *}$ with probability $\left(1-G\left(c^{* *}\right)\right)$. Hence, the same Bertrand-style argument as above shows that in any equilibrium, at least three firms offer $\underline{p}_{T-1}^{\min }=\underline{p}^{* *}$. Thus, a firm earns zero on any subscribers it attracts. This means that the problem facing each firm $j \in\{1, \ldots, n\}$ in the penultimate period is

$$
\Pi_{T-1}^{j}\left(s_{T-1}^{j}\right)=\max _{\left\langle\bar{p}_{T-1}^{j} \in \Re\right\rangle} s_{T-1}^{j}\left(1-G\left(\bar{p}_{T-1}^{j}-\underline{p}^{* *}\right)\right) \bar{p}_{T-1}^{j}+\delta \Pi_{T}^{j}\left(s_{T-1}^{j}\left(1-G\left(\bar{p}_{T-1}^{j}-\underline{p}^{* *}\right)\right)\right)
$$

Differentiating with respect to $s_{T-1}^{j}$ and applying (9), the first-order necessary conditions can be written

$$
\frac{1-G\left(\bar{p}_{T-1}^{j}-\underline{p}^{* *}\right)}{g\left(\bar{p}_{T-1}^{j}-\underline{p}^{* *}\right)}-\left(\bar{p}_{T-1}^{j}-\underline{p}^{* *}\right)=0, \quad j \in\{1, \ldots, n\} .
$$

Again, these conditions are sufficient by Assumption 1. Applying Lemma 2 to this yields $\bar{p}_{T-1}^{j}-\underline{p}^{* *}=c^{* *}$, or $\bar{p}_{T-1}^{j}=\bar{p}^{* *}$. Substituting this into the value function and performing some simple algebra gives

$$
\Pi_{T-1}^{j}\left(s_{T-1}^{j}\right)=s_{T-1}^{j}\left(1-G\left(c^{* *}\right)\right) c^{* *} .
$$

Next, assume that for $j \in\{1, \ldots, n\}, \bar{p}_{t}^{j}=\bar{p}^{* *}$, that at least three firms charge $\underline{p}_{t}^{\mathrm{min}}=\underline{p}^{* *}$, and that

$$
\Pi_{t}^{j}\left(s_{t}^{j}\right)=s_{t}^{j}\left(1-G\left(c^{* *}\right)\right) c^{* *},
$$

for $t=\tau+1, \tau+2, \ldots, T-1$. In fact, it is notationally convenient (and without loss of generality) to suppose $\tau=0$. Then, exactly the same argument as just given for $T-1$ yields the result.

Q.E.D.

Proof of Proposition 3. Assumption 3 implies the following evolution of market shares in the full-participation equilibrium:

$$
s_{\tau+1}^{j}=s_{\tau}^{j}\left(1-G\left(c^{* *}\right)\right)+\frac{\sum_{k \neq j} s_{\tau}^{k}}{n-1} G\left(c^{* *}\right), \quad \tau=0, \ldots, T-1 .
$$

Noting that

$$
\sum_{k \neq j} s_{\tau}^{k}=1-s_{\tau}^{j}
$$

gives

$$
s_{\tau+1}^{j}=\frac{1}{n-1} G\left(c^{* *}\right)+s_{\tau}^{j}\left(1-\frac{n}{n-1} G\left(c^{* *}\right)\right), \quad \tau=0, \ldots, T-1 .
$$

Set $\tau+1=t$ and apply this formula recursively to get

$$
s_{t}=\left(\frac{1}{n-1} G\left(c^{* *}\right)\right) \sum_{\tau=0}^{t-1}\left(1-\frac{n}{n-1} G\left(c^{* *}\right)\right)^{\tau}+s_{0}^{j}\left(1-\frac{n}{n-1} G\left(c^{* *}\right)\right)^{\prime} .
$$

By Assumption 4,

$$
\sum_{\tau=0}^{t-1}\left(1-\frac{n}{n-1} G\left(c^{* *}\right)\right)^{\mathrm{r}}=\left(\frac{n-1}{n G\left(c^{* *}\right)}\right)\left(1-\left(1-\frac{n}{n-1} G\left(c^{* *}\right)\right)^{t}\right),
$$

from which the claim follows.

O RAND 2003. 
Proof of Lemma 3. Differentiability follows from Assumption 5, which implies the second-order sufficient condition for a maximum. To establish monotonicity, differentiate (13) with respect to $\beta$ to get

$$
\frac{d}{d \bar{p}_{1}}\left(\beta g^{H}\left(\bar{p}_{1}\right) \gamma^{H}\left(\bar{p}_{1}\right)+(1-\beta) g^{L}\left(\bar{p}_{1}\right) \gamma^{L}\left(\bar{p}_{1}\right)\right) \times \frac{d \bar{p}_{1}}{d \beta}+g^{H}\left(\bar{p}_{1}\right) \gamma^{H}\left(\bar{p}_{1}\right)-g^{L}\left(\bar{p}_{1}\right) \gamma^{L}\left(\bar{p}_{1}\right)=0 .
$$

The first derivative in this expression is strictly negative, as just noted. Hence, monotonicity will follow if

$$
g^{H}\left(\bar{p}_{1}\right) \gamma^{H}\left(\bar{p}_{1}\right)>g^{L}\left(\bar{p}_{1}\right) \gamma^{L}\left(\bar{p}_{1}\right)
$$

Applying Assumptions 1 and 6 to (13) gives

$$
\beta g^{H}\left(\bar{p}_{1}\right) \gamma^{H}\left(\bar{p}_{1}\right)>0
$$

and

$$
(1-\beta) g^{L}\left(\bar{p}_{1}\right) \gamma^{L}\left(\bar{p}_{1}\right)<0 .
$$

The final part of the claim follows from substituting $\beta=0$ and $\beta=1$ into (13) and dividing through by the relevant density.

Q.E.D.

Proof of Proposition 4. The optimality of consumer and firm behavior in period one conditional on beliefs was established in Lemma 3. Suppose that a monotonic solution to (15) exists. Then, the cutoff functions are optimal for a consumer in period zero provided that he does not prefer to switch from firm $j$ to a firm charging $\underline{p}_{0}>\underline{p}_{0}^{j^{\prime}}$. This follows from Assumption 7 because a consumer who makes such a switch is believed to be type $H$ with probability $\alpha>\beta^{r}$ and, therefore, earns expected utility

$$
v-\underline{p}_{0}-c+\delta U_{1}^{\theta}(\alpha)<v-\underline{p}_{0}^{j^{\prime}}-c+\delta U_{1}^{\theta}\left(\beta^{\gamma}\right) .
$$

Hence, if a monotonic solution to (15) exists, then optimal consumer behavior in period zero is characterized by the cutoff functions $K^{H}(x)$ and $K^{L}(x)$.

The next thing to establish, therefore, is that a solution, $\left(K^{H}(x), K^{L}(x)\right)$, to (15) exists, and that $\delta Q_{L}^{L}<1$ implies that $K^{\theta}(x)$ is nondecreasing.

To establish existence, define for $\theta \in\{H, L\}$ and all $\left(k^{H}, k^{L}\right) \in[0,1]^{2}$ the function

$$
F^{\theta}\left(k^{H}, k^{L}\right)= \begin{cases}1, & \text { if } x+\delta Q^{\theta}\left(k^{H}, k^{L}\right)>1 \\ x+\delta Q^{\theta}\left(k^{H}, k^{L}\right), & \text { if } x+\delta Q^{\theta}\left(k^{H}, k^{L}\right) \in[0,1] \\ 0, & \text { if } x+\delta Q^{\theta}\left(k^{H}, k^{L}\right)<0\end{cases}
$$

The function $\left(F^{H}, F^{L}\right)$ is well defined, continuous, and maps $[0,1]^{2}$ to $[0,1]^{2}$. Hence, by Brouwer's fixed-point theorem, there exists

$$
\left(k_{0}^{H}, k_{0}^{L}\right)=\left(F^{H}\left(k_{0}^{H}, k_{0}^{L}\right), F^{L}\left(k_{0}^{H}, k_{0}^{L}\right)\right) .
$$

If $\left(k_{0}^{H}, k_{0}^{L}\right) \in(0,1)^{2}$, then it is obviously a solution to (15). Also, if $x \geq 1$ (or $\left.x \leq 0\right)$, then $k_{0}^{H}=k_{0}^{L}=1\left(k_{0}^{H}=k_{0}^{L}=0\right.$ ) is a solution. Hence, suppose $x \in(0,1)$. In this case, it must be shown that fixed points cannot occur on the boundary. This is done by assuming that a fixed point does occur on the boundary and showing that this leads to a contradiction in each of the six possible cases.

Case l. $\left(1=k_{0}^{H}=k_{0}^{L}\right)$. In this case, Assumption 7 gives $\beta^{N}=\beta^{Y}=\alpha$. Then, Lemma 3 implies $Q^{\theta}\left(k_{0}^{H}, k_{0}^{L}\right)=0$. This along with $x<1$ yields $x+\delta Q^{\theta}\left(k_{0}^{H}, k_{0}^{L}\right)<1$, which contradicts $k_{0}^{H}=k_{0}^{L}=1$.

Case 2. $\left(1=k_{0}^{H}>k_{0}^{L}\right)$. In this case, $0=\beta^{N}<\beta^{Y}$. Then, Lemma 3 implies $Q^{\theta}\left(k_{0}^{H}, k_{0}^{L}\right)<0$. This along with $x<1$ yields $x+\delta Q^{H}\left(k_{0}^{H}, k_{0}^{L}\right)<1$, which contradicts $k_{0}^{H}=1$.

Case 3. $\left(1=k_{0}^{L}>k_{0}^{H}\right)$. In this case, $1=\beta^{N}>\beta^{Y}$. Then, Lemma 3 implies $Q^{\theta}\left(k_{0}^{H}, k_{0}^{L}\right)>0$. But stochastic dominance gives $Q^{H}\left(k_{0}^{H}, k_{0}^{L}\right)>Q^{L}\left(k_{0}^{H}, k_{0}^{L}\right)$, which contradicts $k_{0}^{L}>k_{0}^{H}$.

Case 4. $\left(0=k_{0}^{H}=k_{0}^{L}\right)$. In this case, Assumption 7 gives $\beta^{N}=\beta^{Y}=\alpha$. Then, Lemma 3 implies $Q^{\theta}\left(k_{0}^{H}, k_{0}^{L}\right)=0$. This along with $x>0$ yields $x+\delta Q^{\theta}\left(k_{0}^{H}, k_{0}^{L}\right)>0$, which contradicts $k_{0}^{H}=k_{0}^{L}=0$.

Case 5. $\left(0=k_{0}^{H}<k_{0}^{L}\right)$. In this case, $0=\beta^{Y}<\beta^{N}$. Then, Lemma 3 implies $Q^{\theta}\left(k_{0}^{H}, k_{0}^{L}\right)>0$. This along with $x>0$ yields $x+\delta Q^{H}\left(k_{0}^{H}, k_{0}^{L}\right)>0$, which contradicts $k_{0}^{H}=0$.

- RAND 2003 
Case 6. $\left(0=k_{0}^{L}<k_{0}^{H}\right)$. In this case, $1=\beta^{Y}>\beta^{N}$. Then, Lemma 3 implies $Q^{\theta}\left(k_{0}^{H}, k_{0}^{L}\right)<0$. But stochastic dominance gives $Q^{H}\left(k_{0}^{H}, k_{0}^{L}\right)<Q^{L}\left(k_{0}^{H}, k_{0}^{L}\right)$, which contradicts $k_{0}^{L}<k_{0}^{H}$.

Hence, any fixed point of $\left(F^{H}, F^{L}\right)$ must be a solution to (15), and at least one fixed point exists for any value of $x$. Parameterize the solution by $\left(K^{H}(x), K^{L}(x)\right)$.

Next, simple calculations establish $Q_{H}^{\theta} \leq 0$ and $Q_{L}^{\theta} \geq 0$. In addition, stochastic dominance implies $Q_{H}^{H} \leq Q_{H}^{L}$ and $Q_{L}^{L} \leq Q_{L}^{H}$. Now, implicit differentiation of (15) and application of Cramer's rule yields

$$
\frac{d k^{H}}{d x}=\frac{1-\delta Q_{L}^{L}+\delta Q_{L}^{H}}{\left(1-\delta Q_{H}^{H}\right)\left(1-\delta Q_{L}^{L}\right)-\delta^{2} Q_{L}^{H} Q_{H}^{L}}
$$

and

$$
\frac{d k^{L}}{d x}=\frac{1-\delta Q_{H}^{H}+\delta Q_{H}^{L}}{\left(1-\delta Q_{H}^{H}\right)\left(1-\delta Q_{L}^{L}\right)-\delta^{2} Q_{L}^{H} Q_{H}^{L}} .
$$

Given the preceding observations, the numerators of these expressions are positive. Moreover, a sufficient condition for the denominators to be positive is clearly $\delta Q_{L}^{L}<1$.

For the next part of the proof, consider firm behavior in period zero. Given $p_{0}^{\dagger}$, the extreme-value theorem ensures existence of the best response $\bar{p}_{0}^{\dagger}$. To see that $\underline{p}_{0}^{\dagger}$ also exists, fix $\bar{p}_{0}^{\dagger}$. If $-\underline{p}_{0} \leq-\bar{p}_{0}^{\dagger}$ or $-\underline{p}_{0} \geq 1-\bar{p}_{0}^{\dagger}$, then

$$
\delta \pi_{1}\left(\beta^{Y}\left(K^{H}\left(\bar{p}_{0}^{\dagger}-\underline{p}_{0}\right), K^{L}\left(\bar{p}_{0}^{\dagger}-\underline{p}_{0}\right)\right)\right)=\delta \pi_{1}(\alpha)
$$

because $K^{\theta}(x)=0$ for $x \leq 0$ (no one switches) and $K^{\theta}(x)=1$ for $x \geq 1$ (everyone switches). Hence, $\delta \pi_{1}\left(\beta^{Y}\left(K^{H}\left(\bar{p}_{0}^{\dagger}-\underline{p}_{0}\right), K^{L}\left(\bar{p}_{0}^{\dagger}-\underline{p}_{0}\right)\right)\right)$ crosses the 45 -degree line at least once, which establishes existence of $\underline{p}_{0}^{\dagger}$.

Finally, it must be shown that it is an equilibrium for at least three firms (the active firms) to charge $\underline{p}_{0}^{\min }=\underline{p}_{0}^{\dagger}$. First note that all firms make expected discounted profit of zero from switchers under the proposed equilibrium. Now, if one of the active firms deviates to $\underline{p}_{0}>\underline{p}_{0}^{\dagger}$, then it will attract no switchers. Also, if any firm deviates to $\underline{p}_{0}<\underline{p}_{0}^{\dagger}$, then it will attract all of the switchers from other firms. Recall, however, that $\underline{p}_{0}^{\dagger}$ is the lowest price at which a firm expects to break even; i.e., $\underline{p}_{0}<\underline{p}_{0}^{\dagger}$ implies

$$
\underline{p}_{0}+\delta \pi_{1}\left(\beta^{\gamma}\left(K^{H}\left(\bar{p}_{0}^{\dagger}-\underline{p}_{0}\right), K^{L}\left(\bar{p}_{0}^{\dagger}-\underline{p}_{0}\right)\right)\right)<0
$$

Q.E.D.

\section{Two technical lemmas.}

Lemma Al (skimming). Consider a type- $\theta$ subscriber who faces date-zero prices of $\bar{p}_{0}$ and $\underline{p}_{0}$ and whose date-zero switching cost realization is $c$. If this individual does not switch suppliers in period zero in equilibrium, then neither does any type- $\theta$ individual who faces the same prices and has a higher switching-cost realization $c^{\prime}>c$.

Proof. By way of contradiction, suppose that an individual with $c$ prefers not to switch,

$$
v-\bar{p}_{0}+\delta U_{1}^{\theta}\left(\beta^{N}\right) \geq v-\underline{p}_{0}-c+\delta U_{1}^{\theta}\left(\beta^{Y}\right),
$$

and that an individual with $c^{\prime}>c$ prefers to switch,

$$
v-\bar{p}_{0}+\delta U_{1}^{\theta}\left(\beta^{N}\right) \geq v-\underline{p}_{0}-c^{\prime}+\delta U_{1}^{\theta}\left(\beta^{Y}\right) .
$$

Subtracting the second inequality from the first one yields $c^{\prime}-c \leq 0 . \quad$ Q.E.D.

Lemma A2 (screening). Although $K^{H}(x) \geq K^{L}(x), G^{H}\left(K^{H}(x)\right) \leq G^{L}\left(K^{L}(x)\right)$.

Proof. By way of contradiction, suppose $G^{H}\left(K^{H}(x)\right)>G^{L}\left(K^{L}(x)\right)$. Then, $\beta^{Y}\left(K^{H}(x), K^{L}(x)\right) \geq \beta^{N}\left(K^{H}(x), K^{L}(x)\right)$ and (by Lemma 3) $\bar{p}_{1}\left(\beta^{Y}\right) \geq \bar{p}_{1}\left(\beta^{N}\right)$. Now, write out (15) separately for $\theta=H$ and $\theta=L$ and subtract one equation from the other to get

$$
K^{H}(x)-K^{L}(x)=\int_{\bar{p}_{1}\left(\beta^{Y}\right)}^{\bar{p}_{1}\left(\beta^{N}\right)}\left(G^{L}(c)-G^{H}(c)\right) d c .
$$

Consider the integral in this expression. The integrand is positive by stochastic dominance, but the lower limit of integration is weakly greater than the upper limit. Hence, the integral is nonpositive, implying $K^{H}(x) \leq K^{L}(x)$ and, hence, $G^{H}\left(K^{H}(x)\right) \leq G^{L}\left(K^{L}(x)\right) . \quad$ Q.E.D.

O RAND 2003 . 


\section{References}

ARmstrong, M. AND Vickers, J. “Competitive Price Discrimination.” RAND Journal of Economics, Vol. 32 (2001), pp. 579-605.

Ausubel, L.M. "The Failure of Competition in the Credit Card Market." American Economic Review, Vol. 81 (1991), pp. $50-81$.

BAILEY, J. AND KILMAN, S. "Taking Credit: Here's What's Driving Some Lenders Crazy: Borrowers Who Think." Wall Street Journal, February 20, 1998, p. A1.

BEGGS, A.W. AND KLEMPERER, P. “Multi-period Competition with Switching Costs.” Econometrica, Vol. 60 (1992), pp. $651-666$.

BORENSTEIN, S. "Price Discrimination in Free-Entry Markets." RAND Journal of Economics, Vol. 16 (1985), pp. 380-397.

BRITO, D.L. AND HARTLEY, P.R. "Consumer Rationality and Credit Cards.” Journal of Political Economy, Vol. 103 (1995), pp. $400-433$.

Bulkeley, W.M. "Verbind Watches Shoppers to Predict Next Move." Wall Street Journal, July 1, 1999, p. B6.

CHEN, Y.M. "Paying Customers to Switch." Journal of Economics and Management Strategy, Vol. 6 (1997), pp. 877-897.

ECONOMIDES, N. "The Telecommunications Act of 1996 and Its Impact." Japan and the World Economy, Vol 11 (1999), pp. $455-483$.

FARRELl, J. AND Klemperer, P. "Coordination and Lock-In: Competition with Switching Costs and Network Effects." In M. Armstrong and R. Porter, eds., The Handbook of Industrial Organization: III. New York: North-Holland, forthcoming.

—_ AND SHAPIRO, C. "Dynamic Competition with Switching Costs." RAND Journal of Economics, Vol. 19 (1988), pp. 123-137.

FudenberG, D. AND Tirole, J. “Customer Poaching and Brand Switching.” RAND Journal of Economics, Vol. 31 (2000), pp. $634-657$.

JeITSChKo, T.D. AND MIRMAN, L.J. "Information and Experimentation in Short-Term Contracting." Economic Theory, Vol. 19 (2002), pp. 311-331.

KELLER, J.J. "Telecommunications: Best Phone Discounts Go to Hardest Bargainers." Wall Street Journal, February 13, 1997, p. B1.

KEnNan, J. "Repeated Bargaining with Persistent Private Information." Review of Economic Studies, Vol. 68 (2001), pp. 719-755.

KlemPereR, P. “Competition When Consumers Have Switching Costs: An Overview with Applications to Industrial Organization, Macroeconomics, and International Trade." Review of Economic Studies, Vol. 62 (1995), pp. 515539.

. "The Competitiveness of Markets with Switching Costs." RAND Journal of Economics, Vol. 18 (1987a), pp. 137-150.

"Entry Deterrence in Markets with Consumer Switching Costs." Economic Journal, Vol. 97 (1987b), pp. 99-1 17.

. "Markets with Consumer Switching Costs." Quarterly Journal of Economics, Vol. 102 (1987c), pp. 375-394.

KNITTEL, C.R. "Interstate Long Distance Rates: Search Costs, Switching Costs, and Market Power." Review of Industrial Organization, Vol. 12 (1997), pp. 519-536.

LOCAY, L. AND RodRIGUEZ, A. "Price Discrimination in Competitive Markets." Journal of Political Economy, Vol. 100 (1992), pp. 954-965.

MCAFEE, R.P. AND MCMILLAN, J. “Auctions and Bidding." Journal of Economic Literature, Vol. 25 (1987), pp. 699-738.

NILSSEN, T. "Two Kinds of Consumer Switching Costs." RAND Journal of Economics, Vol. 23 (1992), pp. 579-589.

PIETRUCHA, B. "FCC Releases Report on Long-Distance Market." Newsbytes, March 31, 1997, www.newsbytes.com.

Prendergast, C. AND STOLE, L. "Impetuous Youngsters and Jaded Old-Timers: Acquiring a Reputation for Learning." Journal of Political Economy, Vol. 104 (1996), pp. 1105-1134.

Ross, S.M. Introduction to Stochastic Dynamic Programming. New York: Academic Press, 1983.

Rossi, P.E., MCCulloch, R.E., AND AllenBy, G.M."The Value of Purchase History Data in Target Marketing." Marketing Science, Vol. 15 (1996), pp. 321-340.

SCHLesinger, H. AND VON DER SChUlenbuRG, J.-M.G. "Consumer Information and Decisions to Switch Insurers." Journal of Risk and Insurance, Vol. 60 (1993), pp. 591-615.

SCHWARTZ, M. "Telecommunications Reform in the United States: Promises and Pitfalls." In P.J.J. Welfens and G. Yarrow, eds., Telecommunications and Energy in Systemic Transformation. New York: Springer, 1997.

Shaffer, G. AND Zhang, Z.J. "Pay to Switch or Pay to Stay: Preference-Based Price Discrimination in Markets with Switching Costs." Joumal of Economics and Management Strategy, Vol. 9 (2000), pp. 397-424.

SHARPE, S.A. "The Effect of Consumer Switching Costs on Prices: A Theory and Its Application to the Bank Deposit Market." Review of Industrial Organization, Vol. 12 (1997), pp. 79-94.

STANGo, V. "Pricing with Consumer Switching Costs: Evidence from the Credit Card Market." Mimeo, Federal Reserve Bank of Chicago, 2001

VARIAN, H.R. "Price Discrimination and Social Welfare." American Economic Review, Vol. 75 (1985), pp. 870-875. . "Price Discrimination." In R. Schmalensee and R.D. Willig, eds., The Handbook of Industrial Organization. New York: North-Holland, 1989.

O RAND 2003 
VAN ACKERE, A. AND REYNIERS, D.J. "Trade-Ins and Introductory Offers in a Monopoly." RAND Journal of Economics, Vol. 26 (1995), pp. 58-74.

VILLAS-BOAS, J.M. “Dynamic Competition with Customer Recognition.” RAND Journal of Economics, Vol. 30 (1999), pp. 604-631.

vON WeIzSACKER, C.C. "The Costs of Substitution.” Econometrica, Vol. 52 (1984), pp. 1085-1116. 
Copyright of RAND Journal of Economics is the property of RAND Journal of Economics. The copyright in an individual article may be maintained by the author in certain cases. Content may not be copied or emailed to multiple sites or posted to a listserv without the copyright holder's express written permission. However, users may print, download, or email articles for individual use. 